\title{
Bovid ecomorphology and hominin paleoenvironments of the Shungura Formation, lower Omo River Valley, Ethiopia
}

Thomas W. Plummer ${ }^{1}$, Joseph V. Ferraro ${ }^{2}$, Julien Louys ${ }^{3}$, Fritz Hertel ${ }^{4}$, Zeresenay Alemseged $^{5}$, René Bobe ${ }^{6}$, L. C. Bishop ${ }^{7}$

${ }^{1}$ Department of Anthropology, Queens College, CUNY and NYCEP, 65-30 Kissena Boulevard, Flushing, NY 11367 USA, thomas.plummer@qc.quny.edu

${ }^{2}$ Department of Anthropology and Institute of Archeology, Baylor University, Waco, TX USA, joseph_ferraro@baylor.edu

${ }^{3}$ Department of Archaeology and Natural History, Australian National University, Canberra ACT, Australia, julien.louys@anu.edu.au

${ }^{4}$ Department of Biology, California State University, Northridge, CA 91330-8303 USA, fritz.hertel@csun.edu

${ }^{5}$ Department of Anthropology, California Academy of Sciences, 55 Concourse Drive, San Francisco, CA 94118 USA, zalemseged@cakacademy.org

${ }^{6}$ Department of Anthropology and CASHP, George Washington University, 2110 G Street, NW, Washington DC 20052 USA, bobe@gwu.edu

${ }^{7}$ Research Centre for Evolutionary Anthropology and Palaeoecology, School of Natural Sciences and Psychology, Liverpool John Moores University, Byrom Street, Liverpool L3 3AF UK, l.c.bishop@ljmu.ac.uk

44 pages

9 figures

10 tables

1 Supplementary file

KEYWORDS: East Africa, palaeoecology, hominin, Bovidae, Pliocene, Pleistocene 


\section{Abstract}

The Shungura Formation in the lower Omo River Valley, southern Ethiopia, has yielded an important paleontological and archaeological record from the Pliocene and Pleistocene of eastern Africa. Fossils are common throughout the sequence and provide evidence of paleoenvironments and environmental change through time. This study developed discriminant function ecomorphology models that linked astragalus morphology to broadly defined habitat categories (open, light cover, heavy cover, forest, and wetlands) using modern bovids of known ecology. These models used seven variables suitable for use on fragmentary fossils and had overall classification success rates of $>82 \%$. Four hundred and one fossils were analyzed from Shungura Formation members B through G (3.4 to 1.9 million years ago). Analysis by member documented the full range of ecomorph categories, demonstrating that a wide range of habitats existed along the axis of the paleo-Omo River. Heavy cover ecomorphs, reflecting habitats such as woodland and heavy bushland, were the most common in the fossil sample. The trend of increasing open cover habitats from Members C through F suggested by other paleoenvironmental proxies was documented by the increase in open habitat ecomorphs during this interval. However, finer grained analysis demonstrated considerable variability in ecomorph frequencies over time, suggesting that substantial short-term variability is masked when grouping samples by member. The hominin genera Australopithecus, Homo, and Paranthropus are associated with a range of ecomorphs, indicating that all three genera were living in temporally variable and heterogeneous landscapes. Australopithecus finds were predominantly associated with lower frequencies of open habitat ecomorphs, and high frequencies of heavy cover ecomorphs, perhaps indicating a more woodland focus for this genus. 


\section{Introduction}

The habitat preferences of fauna found at paleontological and archaeological sites can be used to infer the paleoenvironments that existed at particular places and times and assist in reconstructing hominin habitat preferences by inference. We reconstructed habitat availability during the deposition of the Omo Shungura Formation using ecomorphology of fossil antelope (Mammalia: Bovidae) astragali. The ecomorphological approach relies on the links between morphology and environment or substrate, rather than relying on taxonomic uniformitarianism in habitat preference. It also allows an abundance-based environmental reconstruction, whereas many synecological methods used to predict environments rely on the presence or absence of particular taxa (e.g., Andrews et al., 1979; Reed, 1997; Louys et al., 2015).

Previous work has demonstrated that bovid astragali can be classified successfully into habitat preference categories by analysis of morphologies associated with particular habitat preferences (DeGusta and Vrba, 2003; Plummer et al., 2008; Barr, 2014). This method can be used to analyze fossil bovid astragali with known stratigraphic provenance. Relative abundance of fossil astragali assigned to different habitat preferences (relative ecomorph abundance) can, subject to taphonomic analysis, be used as a proxy for the relative abundance of the types of preferred vegetation cover, allowing us to infer their prevalence regionally during the stratigraphic interval of deposition (Kappelman, 1988; Plummer and Bishop, 1994; Kappelman et al., 1997; Kovarovic and Andrews, 2007; Bishop et al., 2011).

We examined the relative frequency of ecomorphs indicating habitat preference in Members B through G (3.4 - 1.9 million years ago (Ma)) of the Shungura Formation. Ecomorph abundance was calculated at different stratigraphic and temporal scales to examine the extent to which these abundances fluctuated through time. This provided an independent 
line of paleoenvironmental evidence to compare with other indicators of Shungura Formation habitat presence and relative availability.

\section{Geological and paleoenvironmental background of the Shungura Formation}

The Omo-Turkana Basin includes the Lake Turkana Basin in northern Kenya as well as the lower Omo River Valley in southern Ethiopia (Fig. 1). Systematic investigation of the lower Omo Valley deposits was undertaken by the International Omo Research Expedition, established in 1966, by separate French, American and Kenyan teams, although the Kenyan team quickly changed its focus to Koobi Fora. The region is known for its rich Pliocene and Pleistocene paleontological and archaeological records. Three major geological formations, the Shungura, Usno, and Mursi, were recognized in the stratigraphic sequence, and these have yielded over 50,000 fossils, including 220 hominin specimens (Alemseged, 2003). The Shungura Formation has an aggregate thickness of $766 \mathrm{~m}$ of sediment divided into 12 members, from oldest to youngest: Basal, A, B, C, D, E, F, G, H, J, K, and L (Fig. 1). It covers a time span from 3.6 to 1.16 Ma (Alemseged, 2003) and each member begins with a volcanic tuff bearing the same letter as the member. Further lithological subdivisions within each member, termed units, are numbered from bottom to top of each member. For example, the fourteenth unit from the base of Member G is designated Unit G-14.

The Shungura Formation has five major depositional phases, starting with lacustrine deposition in the first unit of the Basal Member (Bobe and Eck, 2001). Fluvial deposition predominated between the second unit of the Basal Member and Unit G-13. Lacustrine conditions returned in the third major depositional phase, from Units G-14 to G-27. The fourth phase saw the resumption of fluvial deposition from G-28 to L-6, and the final phase was lacustrine from L-7 to L-9.

The Shungura Formation is one of the best studied sequences in eastern Africa, and its paleoenvironments have been extensively researched. A variety of methods (sedimentological 
analysis of depositional environments, analysis of pollen and macrobotanical fossils, analyses of microfaunal and macrofaunal taxa with specific habitat preferences, changes in faunal diversity and the relative abundances of taxa over time, correspondence analysis of macromammalian faunal abundances, stable isotopic analyses of paleosol carbonates to reconstruct vegetation cover, and stable isotopic analyses of enamel to indicate diet) have been used to reconstruct its paleoenvironmental history (Bobe and Eck, 2001; Bobe et al., 2002; Alemseged, 2003; Bobe and Behrensmeyer, 2004; Bobe, 2006; Bobe et al., 2007; Bobe and Leakey, 2009; Bobe, 2011; Levin et al., 2011). Study of fossil plants suggests that a mosaic of forest (both moist, evergreen forests with epiphytes, and drier deciduous forests with few epiphytes), woodlands, and grasslands in varying proportions characterized the paleo-Omo environs (Bonnefille and Dechamps, 1983). Typha pollen provides evidence of wetlands, and taxa from the Chenopodiaceae and Amaranthaceae groups provide evidence of arid conditions. The discontinuous paleobotanical and microfaunal records suggest that there was a drying trend from Member C to Member F (Bobe and Eck, 2001).

Taxon-based analysis of the bovid fossil samples suggests that there was a transition around 2.8 Ma from wet, closed environments in Member B to closed but dry environments in Member C, and a drying trend from Members D through F (Bobe and Eck, 2001). The shift from predominantly moist to drier closed environments at 2.8 Ma corresponds to an increase in species richness and a rapid change in taxonomic abundance, with a particularly large increase in the abundance of species in the tribe Tragelaphini (kudu and allies). Analyses of bovid tribes and suid and primate genera indicate an interval of relative faunal stability from 2.7 Ma to 2.5 Ma, followed by greater variability in the Omo fauna from 2.5 to 2.1 Ma (Bobe et al., 
2002). After 2.5 Ma, taxa associated with secondary grasslands became more abundant than those associated with forests, and at 2.35 Ma (Member F) there was a slight increase in taxa indicative of open grasslands (Bobe and Leakey, 2009). At approximately 2.3 Ma in lower Member G, bovid diversity and abundance were exceptionally high, possibly reflecting greater environmental heterogeneity (Bobe and Eck, 2001), with evidence for an expansion of edaphic grassland (Alemseged, 2003). In upper Member G there was a major shift in depositional environment as a large lake formed in the valley. There was also an increase in open grassland-indicating taxa, although these still comprised less than $15 \%$ of the macromammalian faunal sample, suggesting that environmental heterogeneity remained pronounced (Bobe and Behrensmeyer, 2004). The faunal and isotopic records indicate that the lower Omo Valley had higher proportions of woodland and forest through time than either the eastern or western sides of the Lake Turkana Basin (Bobe and Behrensmeyer, 2004; Bobe and Leakey, 2009; Levin et al., 2011), with significant increases in grassland vegetation not occurring until after $2 \mathrm{Ma}$, in Members H through L.

\section{Shungura Formation taphonomy and faunal change}

Bobe and Eck (2001) examined faunal change in the Shungura Formation and concluded that it was a real phenomenon unlikely to have resulted from taphonomic processes. In Member B to lower Member G fluvial deposition predominated, and isolated teeth are frequently preserved. When examined by member, the relative frequencies of isolated teeth and analysis of other skeletal parts suggests that the Shungura Formation is essentially isotaphonomic, that is to say, the taphonomic biases remained uniform over time (Bobe and Eck, 2001; Bobe et al., 2002; Bobe and Leakey, 2009; Bobe and Behrensmeyer, 2004). Moreover, no significant association was found between the taxonomic and taphonomic data sets, lending further support to the idea that the two signals are independent of each other (Bobe et al., 2002). 
Because astragali were collected systematically, and taphonomic conditions were consistent through much of the sequence, stability or changes in the relative frequency of different ecomorphs over time provide evidence of how environments changed over time.

\section{Ecomorphology and Shungura paleoenvironments}

The Shungura Formation fossil sample is well suited for ecomorphic analysis, because a long temporal interval is represented, and there is the potential for cross validation with a wide range of existing paleoenvironmental information. Both French and American teams collected bovid postcranial elements, with the American team systematically collecting every bovid astragalus found during its surveys (Bobe and Eck, 2001). Previous paleoenvironmental analyses suggest that complex mosaics of vegetation existed in the valley in the past, creating the possibility that a broad array of ecomorphs were present through the stratigraphic sequence. Studying the ecomorphology of Shungura bovids provides an alternative means of evaluating previous paleoenvironmental research, and it has the potential to add new insights derived from abundance-based criteria. Specifically, the following paleoenvironmental inferences suggested by previous research (e.g., Bobe and Eck, 2001; Bobe et al., 2002; Alemseged, 2003; Bobe and Behrensmeyer, 2004; Bobe, 2006; Bobe et al., 2007; Bobe and Leakey, 2009; Bobe, 2011; Levin et al., 2011) can be investigated here:

1. A spectrum of habitats existed through time in the Shungura Formation sequence, with a relatively high representation of woodland and forest habitats.

2. An environmental shift occurred at approximately 2.8 Ma (between Members B and C), which resulted primarily in a shift from wet, closed environments to dry closed environments. 
3. There was an interval of relative environmental stability from 2.7-2.5 Ma, followed by an increase in habitat variability between 2.5-2.0 Ma.

4. A drying trend existed between Members C and F.

5. Taxa associated with grasslands became more common than those associated with forest after 2.5 Ma, with a small peak in taxa preferring relatively open environments in Member F at approximately 2.35 Ma.

6. Grassland-dominated habitats expanded beginning with upper Member G, and thereafter, with some fluctuation, made up a greater proportion of the overall environment than they had prior to lower Member G.

Here, we improved upon the methodology of Plummer et al. (2008) in several ways. We generated new discriminant function models that require fewer measurements while still maintaining high classification success rates. The reduced variable models reported here are useful for fossil samples as they allow a greater number of fragmentary specimens to be included in analyses and thus increase sample size. Maintaining high success rates across habitat categories is critical to accurately reconstruct the relative proportions of different ecomorphs in fossil samples. We also improved our analysis by integrating a method to determine the extent to which habitat preference and phylogeny interact with respect to morphology (e.g., Louys et al., 2013). Further, we refined the habitat classifications used in previous analyses to better reflect the range of habitats in the African vegetation spectrum. In addition to the four habitat preference categories (open, light cover, heavy cover, and forest) used in the past, the model was expanded to include a fifth category for wetland bovids. This is particularly relevant for the Shungura Formation, as there are sedimentological indications of deltaic and lagoonal environments, as well as Typha pollen, through much of the sequence (Bonnefille and Dechamps, 1983). 


\section{Materials and Methods}

We examined 286 astragali from modern bovids housed in the collections of the American Museum of Natural History (New York, NY), the National Museum of Natural History (Washington, D.C.) and the Natural History Museum (London, UK) (Table 1). We measured adult specimens only, and used only wild-shot specimens whenever possible. Overall, fewer than $5 \%$ of the individuals were from specimens that died in captivity, and many of these had been wild caught. Specimens included thirty-seven modern African bovid species having average body masses between 5 and $228 \mathrm{~kg}$. The largest species of bovid were excluded from our analysis because their large body size impacts their locomotor anatomy and behavior, particularly in response to predators; these animals tend to stand their ground rather than run from predators (Kappleman, 1988; Estes, 1991). Predator avoidance strategies that vary with habitat structure have been argued to be a potentially important influence on ecomorphology for the size range of bovids under consideration here (Kappelman, 1988; Kappelman et al., 1997).

Each bovid taxon was assigned to a habitat preference category based on ethological research (Scott, 1979, 1985; Kappelman, 1986, 1988, 1991; Kappelman et al., 1997) and our personal observations in modern African game reserves (Table 1). The environmental categories used here were open (grassland, arid country, ecotones bordering open country), light cover (light bush, tall grass), heavy cover (heavy bush, woodland), and forest (Kappelman et al., 1997; Plummer et al., 2008). The assignment of bovid taxa to habitat preferences generally followed that of Plummer et al. (2008), except for Madoqua kirkii, which was here assigned to the light cover category following field observations of habitat preferences in its range (Bishop, Plummer, pers. obs). We also used a fifth category, wetland, for Tragelaphus spekei, Kobus leche, and Kobus megaceros, taxa that are known to prefer 
near-water habitats (Table 1). In previous studies using four habitat preference types, these wetland taxa were included in the heavy cover category. However, this is problematic, as it groups taxa preferring woodlands with those preferring near-water environments. We tested the use of a fifth category because sediments deposited in wetland environments appear to be variably present in the Shungura Formation (Bobe and Eck, 2001) and differences in distal limb anatomy linked to locomotion on wetland substrates have been noted in the Bovidae (Köhler, 1993). Wetland taxa were eliminated from the four habitat category discriminant function analysis (DFA).

Regardless of the nature of categories used, it is recognized that African habitats at the spatial scale of interest to our study often form a continuum, and to divide them is a computational necessity rather than a reflection of environmental reality. The sample consisted of 99 specimens from taxa that prefer open habitats, 87 light cover, 27 heavy cover, and 54 forest, with an additional 19 specimens in the wetland-preferring category for our five habitat model.

One of us (LCB) collected measurements on each modern astragalus using digital calipers (Fig. 2; Table 2). These data were $\log _{10}$ transformed in order to similarly scale measurements and indices derived to reflect shape. The logged data were subjected to a quadratic discriminant function analysis (Plummer et al., 2008; Bishop et al., 2011; SYSTAT v. 13). Discriminant function analysis was used to test the relationship between astragalus morphology and habitat preference among modern bovids. Discriminant function analysis is a classification algorithm that classifies cases into previously determined, naturally occurring groups (James, 1985). In this case an equation (or function) is derived, which best discriminates among habitat preference groups using astragalus measurements and indices from a sample of modern bovids with known habitat preferences. The variables used are those that best discriminate between the groups to which specimens ultimately will be 
assigned. As in our previous work (e.g., Plummer and Bishop, 1994; Plummer et al., 2008; Bishop et al., 2011) we used quadratic, rather than linear, discriminant function analysis. In linear DFA, identical within-group covariance matrices are pooled to calculate a linear discriminant function (Kovarovic et al., 2011). We used quadratic DFA because significant differences were found among the within-group covariance matrices generated from our sample, violating the requirements of linear DFA. Quadratic DFA models do not require within-group covariance matrices to be identical (James, 1985; Reyment, 1991). The quadratic routine in SYSTAT v. 13 has the additional benefit of automatically limiting collinearity by not allowing variables that are highly correlated with each other to be included in the same model, another factor that affects DFA performance. Canonical coefficients are generated for each analysis that indicate the relative contribution each variable makes to the discrimination among the habitat groups. Probabilities of membership in each predetermined habitat preference category is calculated on the basis of each specimen's generalized squared (Mahalanobis) distance from the centroids of each group. The quadratic DFA assigns each specimen to a habitat preference category by placing it in the group for which its probability of membership is highest.

The same seven variables were used to classify astragali in both 4- and 5habitat category models (Fig. 2, Table 2). This variable list was somewhat different from that used by Plummer et al. (2008) on modern astragali, because certain landmarks or regions of the astragalus were not always preserved in the fossils. We selected variables that were frequently present in fossil specimens so as to maximize the sample size of fossils available for analysis, while preserving the highest possible classification success rate. From the subset of commonly preserved metric variables, we generated models with reasonably high (>82\%) overall success rates. Three 
variables were log-transformed linear measurements: LTARSMLT (the log of the mediolateral dimension of the tarsal articulation), LTAMAP (the log of the anteroposterior dimension of the medial side of the tarsal articulation) and LMINLEN (the log of the minimum length of the astragalus, measured between the central depressions of each trochlea). The remaining four variables were log-transformed dimensionless ratios: LENRA8 (the log of the medial length of the astragalus divided by the log of the minimum breadth of the tarsal articulation LMEDLEN/LFOFO), LLENRA21 (the log of the medial length of the astragalus divided by the log of the trochlear diameter of the medial side of the tibial articulation LMEDLEN/LTIMAP), LMLRAT3 (the log of the maximum mediolateral dimension of the astralagus divided by the log of the minimum breadth of the tarsal articulation TUBML/FOFO), and DEPRA9 (the mediolateral dimension of the tarsal articulation divided by the maximum depth of the astragalus TARSMLT/MAXSI). Summary statistics for the measurements and ratios are provided in Table 3.

The same measurements were taken on the Omo fossil astragali collected by the French and American expeditions housed in the National Museum of Ethiopia in Addis Ababa by one of us (JF). We examined interobserver error before and after the Omo fossil dataset was measured (8 measurements on 11 astragali). Before Omo data collection, mean interobserver error (between JF and LCB) was 0.9\%. After Omo data collection, mean interobserver error was $0.7 \%$. The mean intraobserver error before and after Omo data collection was $0.7 \%$. A total of 774 fossils with stratigraphic information from the Omo Fossil Database were measured from Members A through L. Four hundred and thirteen of these were sufficiently well preserved for analysis. However, some members had very small sample sizes and were excluded from further consideration. Thus our results concentrate on 401 specimens derived from Members B through $\mathrm{H}$. 
The DFA model generated from the modern sample was applied to fossil "unknowns" to assign them to a habitat preference category. Each fossil was placed in the habitat category for which it had the highest probability of membership, based on the smallest generalized squared (Mahalanobis) distance to the group centroid. We also used the set stratigraphic intervals of Bobe et al. (2002) to approximate shorter and more equal-time units, and thus minimize time-averaging effects within the constraints of stratigraphic resolution. Relative proportions of habitat preferences were plotted by member and by stratigraphic interval to assess ecomorph frequency change over time using both the 4- and 5-habitat models (Figs. 3-5).

\section{Morphological convergence and divergence}

In order to satisfy the requirements of ecomorphological analysis, the morphological characteristics being examined must be a function of an organism's ecology rather than just a result of its phylogenetic heritage (Barr and Scott, 2013; Louys et al., 2013; Scott and Barr, 2014). One of the most common comparative methods used to account for interspecific autocorrelation resulting from phylogeny is the phylogenetic generalised least squares (PGLS) technique. This technique represents a modified form of generalised least squares, and allows an assessment of the amount of phylogenetic signal any morphological variable might have. PGLS was recently championed as a way of determining the 'phylogenetic risk' of any morphological trait being considered for ecomorphological analysis (Scott and Barr, 2014). The use of this approach does not require that traits with high phylogenetic 'risks' be immediately discarded, but rather highlights them so that they are considered within the context of functionally relevant observations. Nevertheless, implicit in this approach is the presumption that variables with strong phylogenetic 
signals are undesirable for ecomorphological models and that phylogenetic 'risk' should be minimized or eliminated.

Habitat preferences may be strongly correlated with phylogenetic signals, and so to disregard any corresponding morphological traits would negatively impact the accuracy of subsequent ecomorphological analyses. For example, the radiation of alcelaphin bovids produced closely related species which share the same habitat preferences and presumably habitat-related functional morphology (Hernández Fernández and Vrba, 2005). Eliminating morphological traits which are highly correlated with both phylogeny and ecology would reduce the accuracy of resultant ecomorphic models. Conversely, traits may be ‘evolutionarily labile’, whereby closely related species are not more similar than would be expected under common evolutionary models such as Brownian motion (Blomberg et al., 2003; Symonds and Blomberg, 2014). In such cases, comparative methods such as PGLS run the risk of over-correcting for phylogeny (Westoby et al., 1995; Björklund, 1997; Rheindt et al., 2004).

An alternative approach was recently outlined by Louys et al. (2013). Rather than attempting to determine the amount of phylogenetic signal present in any particular trait, these authors argued that the only criteria a valid ecomorphological analysis should satisfy are the assumptions of morphological convergence and divergence relative to phylogeny. These two conditions underlie the entire rationale for ecomorphology (Kappelman et al., 1997; DeGusta and Vrba, 2003; Plummer et al., 2008). Louys et al. (2013) described convergence as the condition observed when two distantly related species having the same habitat preference are more similar morphologically than two similarly related species that prefer different habitats. That is to say, animals that are distantly related have converged upon a similar morphological solution to the same habitat-related environmental constraint. The condition of divergence occurs when two closely related species having different habitat 
preferences are more different morphologically than two similarly related species that share the same habitat preference. Thus, closely related taxa that prefer different habitats have diverged morphologically as a result of these preferences. Under this approach, both 'high risk' and 'low risk' traits can be comfortably included in any ecomorphological analysis, provided that the overall morphospace exhibits both convergence and divergence. This approach has the added advantage of accommodating traits that might be evolutionarily labile, as well as those that might otherwise be discarded due to the amount of phylogenetic signal they exhibit.

We examined the presence of divergence and convergence (DIVCON) in the bovid samples in our 4- and 5-habitat DFAs. Each potential species pair was assigned to one of four categories: (1) closely related sharing the same habitat preference; (2) closely related having different habitat preferences; (3) distantly related sharing the same habitat preference; and (4) distantly related having different habitat preferences. The average morphological differences between species pairs falling in categories (1) and (2) must be significantly different in order to satisfy an assumption of divergence in morphospace. Similarly, the average morphological differences between species pairs falling in categories (3) and (4) must be significantly different in order to satisfy an assumption of convergence in morphospace. For this analysis, the morphological distance was calculated on the basis of the morphospace defined by the DFA. The group centroids for each modern species were determined on the basis of the DFA output, and the distances between the centroids were calculated using PAST version 2.17c (Hammer et al., 2001). The habitat preference categories were used to indicate whether two species shared the same habitat preference (Table 1).

A potential criticism of Louys et al.’s (2013) DIVCON analysis is that it uses a morphospace constructed by a DFA. Since the underlying DFA assumes that 
differences between groups (in our case habitat preferences) are significant, when comparing a set of species with one habitat preference to another set of species with a different habitat preference, significant differences between these groups will always be found . This would be a concern if the DIVCON analysis was only examining the difference between all species in the same habitat versus all species in a different habitat. However, the species are further divided into two other sets, namely closely related or distantly related. There are no a priori reasons why this further division should result in significant differences because relatedness does not form part of the DFA.

We defined closeness of relationship on the basis of mean time of divergence of congeneric species rather than on the mean patristic distance used by Louys et al. (2013). Patristic distance gives an indication of topological distance between species pairs; however, this distance is relative only to the tree topology examined. While divergence times determined from dated phylogenies are also, in part, relative to the tree topology examined, they can be calibrated both by absolute (fossil and molecular estimates) and relative (molecular) dates and therefore provide more accurate estimates of species relatedness than those based on tree topologies alone. We used the dated species-level supertree of Hernández Fernández and Vrba (2005) to determine the degree of relatedness between species. We used supertree data to determine the mean and standard deviation of time since divergence between congeneric African Bovidae. We followed the taxonomic nomenclature of Hernández Fernández and Vrba (2005), with the exceptions of Beatragus, which we considered as a member of Damaliscus, and Damaliscus dorcas, which was not listed by Hernández Fernández and Vrba (2005), but which we considered as part of an unresolved trichotomy with $D$. lunatus and $D$. pygargus. These nomenclatural differences do not affect the calculations of mean divergence time. The mean divergence time between two species in a genus belonging to the African Bovidae was 4.59 Ma, with a standard deviation of $2.94 \mathrm{Ma}$ 
(calculated using all African Bovidae data from Hernández Fernández and Vrba, 2005). We considered each species pair to be closely related if their likely time of divergence fell below the mean best estimate of divergence plus two standard deviations, rounded to the nearest million years. Thus, two species were considered closely related if the time since their divergence from a shared ancestor was less than 11 Ma. While the taxonomic departure from Hernández Fernández and Vrba (2005) means that slightly different divergence times for congeneric species are computed compared to their taxonomic scheme (as our definition of Damaliscus is different), tree topology remains unaffected with respect to degree of relatedness between species belonging to different genera. In any case, we take a very conservative approach to relatedness, and these minor taxonomic differences do not change our overall results. Comparisons among the categories were analyzed by non-parametric Mann-Whitney U-tests, per Louys et al. (2013).

Body mass

We examined the correlations among all log-transformed variables used in the DFA with log femoral length, a commonly used proxy for body size in bovids (Scott, 1985; Kappelman, 1991; Kappelman et al.; 1997; Plummer et al., 2008). We examined both the distributions of size in the modern habitat categories and also the representation of different sized bovids in the fossil sample. This was done to assess whether our discriminant function analyses were driven by body weight (Klein et al., 2010).

\section{Results}

DFA of modern astragali 


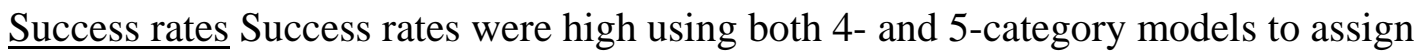
modern bovid astragali to habitat preference categories. The 5-habitat model was newly developed for this analysis of the Omo fossil sample. Results of the 4-habitat model are given in Table 4. This analysis produced three discriminant functions, accounting for $71.5 \%$, $19.2 \%$, and $9.1 \%$ of the variance of the sample, respectively. Multivariate means of the different groups were significantly different $(\mathrm{p}<0.0001)$. The resubstitution classification matrix showed that the DFA using seven variables was highly successful in assigning individual specimens to their correct pre-defined habitat category. For the 4-category model, the overall resubstitution success rate was $88 \%$ correct, with a range of $90 \%$ correct for astragali from bovids preferring open habitat to $83 \%$ for bovids preferring light cover. We further examined reclassification accuracy by jackknife analysis (Table 4). The jackknife matrix summarizes the results of the DFA in which each specimen in the sample was withheld from generating the discriminant function, and the resultant function was then used to predict the habitat preference of the "left out"' specimen. The procedure was carried out 286 times (one for each specimen in the sample), and the summary of the function's predictive success is given in Table 4. A close relationship between resubstitution and jackknife analyses can be used as an indicator of the robustness of the DFA; however the more conservative jackknife method always produces lower success rates.

One indication of the accuracy of predictions made by the DFA is the probability of each case's membership in the group to which it is assigned (e.g., Hertel, 1995; DeGusta and Vrba, 2003; Kovarovic et al., 2011). When the DFA model assigns a specimen, it generates probabilities based on Mahalanobis distances from each group centroid, and assigns it to the group for which its probability of membership is highest. Probabilities range from 0 to $100 \%$; theoretically any case can have equal or near-equal probabilities of membership in each class (e.g., if all probabilities approached 25\%, it would be equivalent to chance assignment in a 4- 
category model). The DFAs developed here assigned specimens to habitat preference categories with high probabilities. For the modern specimens, the mean probability of membership for specimens assigned to the open habitat category was $86 \%, 72 \%$ for light cover, $90 \%$ for heavy cover, and $84 \%$ for the forest preferring bovids.

Results of the DFA for the 5-habitat model are given in Table 5. This analysis produced four discriminant functions, accounting for $68.3 \%, 22.1 \%, 8.7 \%$, and $0.9 \%$ of the variance of the sample, respectively. Multivariate means of the different groups were significantly different $(\mathrm{p}<0.0001)$. Reclassification success rates for the 5-category model were only slightly lower than those for the 4-category model. Overall, $87 \%$ of the specimens were assigned to the correct habitat category using resubstitution. For the most accurately reclassified category (open habitat), 90\% of the bovids were classified correctly. The worstperforming category was the light cover in which $80 \%$ of the cases were classified correctly. The overall jackknife success rate of $82 \%$ demonstrates that the DFA model is robust. The fifth category for wetland-preferring bovids performed well in both resubstitution and jackknife analyses (100\% and 89\% correct, respectively).

Analysis of missed cases Only two of the 34 taxa studied in the 4-habitat DFA model were misclassified more than half the time (Table 6). The first, Addax nasomaculatus, is a hippotragine bovid that inhabits deserts of northern Africa. Two of the fourspecimens were misclassified from their assigned open country habitat preference into the light cover category. Two of the four specimens of Cephalophus nigrifrons, a forest-dwelling cephalophine, were also misclassified into the light cover habitat preference. Both of these taxa were represented by small samples in our analysis, and their relatively high incidence of misclassification may represent natural variation highlighted by the small number of individuals. 
The complete sample of 37 taxa was used for the 5-habitat model, including the wetland preferring species Tragelaphus spekei, Kobus leche, and Kobus megaceros. Four species sampled were misclassified in $50 \%$ or more of their cases (Table 6). The first two, $A$. nasomaculatus and C. nigrifrons, were misclassified in 50\% of cases (two out of four each) as they were in the 4-habitat model. Cephalophus nigrifrons misclassifications followed the same pattern as for the 4-category model, however, one A. nasomaculatus was misclassified as light cover preferring and the other was assigned incorrectly to the wetland category. Cephalophus silvicultor is another forest-dwelling cephalophine that was misclassified in four out of seven (57\%) cases; three into the wetland category and the fourth into the light cover category. Kobus kob, a reduncine that prefers light cover habitats, was misclassified in five of 10 (50\%) cases. Of these, four were into the wetland category, and the fifth into the heavy cover category.

\section{Functional interpretations}

4-habitat model Notched box plots summarize the range of canonical scores for each habitat group (Fig. 6). Virtually the same pattern emerged in the work by Plummer et al. (2008) even with slightly different variables used in their analyses. The first discriminant function accounted for $71.7 \%$ of variance. The open habitat ecomorphs had significantly higher scores on function 1 than the other habitat groups (Fig. 6a). Two variables loaded heavily on function 1; LMINLEN had a high negative loading whereas LTAMAP had a high positive loading (Table 4). A large LTAMAP indicates a wider distal condyle of the astragalus in the antero-posterior direction (Fig. 2), and therefore a wider arc; this gives a greater range of motion within a joint. The total velocity of a limb is the sum of the velocities at each movable joint; therefore increasing mobility at any given joint contributes to the overall speed of movement of the limb (Hildebrand and Goslow, 2001; Plummer et al., 2008). This would be 
advantageous for animals living in more open habitats that rely on speed to outrun their predators. The shortest LMINLEN found in open habitat ecomorphs indicates a more deeply notched astragalus in the proximo-distal direction, mostly in the proximal articulation with the tibia. A deeper groove along the middle axis forms a more tightly interlocking joint and therefore more restricted lateral movement. Restricted lateral movements are found in more cursorial animals (Gentry, 1970; Scott, 1985; Kappelman, 1988; Hildebrand and Goslow, 2001; Plummer et al., 2008), which would be adaptive for open habitat bovids that avoid predation by fleeing from predators.

The second discriminant function accounted for $19.2 \%$ of sample variance (Table 4), with the heavy cover ecomorphs having significantly higher scores than the other three ecomorphs (Fig. 6b). LTARSMLT loaded heavily on this axis, which suggests a wider distal trochlea and more medio-lateral support for the tarso-astragalar articulation (Fig. 2). This would be advantageous in a more closed habitat that would select for greater emphasis on side to side movements (Kappelman, 1988; Hildebrand and Goslow, 2001; Plummer et al., 2008). LTAMAP was also loaded heavily on the axis but with a negative value (Table 4). In this case a narrower distal condyle was typical of heavy cover habitats, supporting the aforementioned interpretation. Given this interpretation, the same would be predicted in the forest forms, which do not appear to differ from the more open habitat forms on this function. In this case, it may be that body size is important because the heavy cover forms are generally larger than the forest forms. Selection for a wider distal articulation (greater support) may be stronger for a larger body size and thus smaller forest forms may tend to be more similar to less closed habitats.

The third discriminant function accounted for only $9.1 \%$ of the sample variance. LMINLEN had a high negative loading whereas LTARSMLT had a high positive loading on this function, both variables that loaded highly on the other discriminant functions (Table 4). 
Our overall functional interpretations were largely supported by Barr (2014) in his recent study of bovid astragali.

5-habitat model For the 5-habitat model we were most interested in how well a DFA model could discriminate bovids preferring a wetland habitat. Interestingly, the same variables that were highly loaded in the 4-habitat model were virtually identical in the 5-habitat model with only minor differences in the actual values but not the loadings (Table 5, Figs. 6d-g). The wetland ecomorph was most similar to the heavy cover and forest categories, and most distinct on function 4 where LTARSMLT was the most heavily loaded positive variable. As discussed above, a wider astragalus would be advantageous for providing greater support to the distal segments, especially for animals with splayed digits that are typical of more wetland or swamp inhabiting bovids (Köhler, 1993).

Morphological convergence and divergence

Evaluation of morphospace For the 4-habitat model, pairs of distantly related species with the same habitat preferences were more similar morphologically than pairs of distantly related species having different habitat preference, demonstrating convergence $(U=9516$; $p<0.001)$ (Fig. 7a). Pairs of closely related species having different habitat preferences were more different morphologically than pairs of closely related species sharing the same habitat preference, demonstrating divergence $(U=118, p=0.02)$ (Fig. 7a). The same results were true for the 5-category model (Fig. 7b). Pairs of distantly related species having the same habitat preferences were more similar than pairs of distantly related species having different habitat preferences $(\mathrm{U}=6426$; $\mathrm{p}<0.001)$. Pairs of closely related species having different habitat preferences were more different morphologically than pairs of closely related species sharing the same habitat preference $(\mathrm{U}=11, \mathrm{p}=0.007)$. The morphospaces created by each 
DFA demonstrably satisfy the assumptions of both convergence and divergence (Fig. 7). This indicated that our analysis is driven by morphology influenced by habitat constraints, and that the DFA is appropriate for ecomorphological analyses seeking to allocate unknown fossil elements to habitat type using astragali. This analysis provides support for an increasing body of work suggesting that although allometry and shared ancestry will influence an organism's phenotype, this phenotype will also be impacted by the environmental constraints under which the organism has to live (Plummer et al., 2008; Walmsley et al., 2012; Louys et al., 2013; Meloro et al., 2013; Barr, 2014).

Fossil astragali For the 4-habitat model, the DFA developed using the modern astragali was used to classify fossil astragali from the Shungura Formation (Supplementary Online Material [SOM], S1). As noted above, our results concentrate on 401 specimens derived from Members B through H. Generally, samples in this paper will be designated by the member or unit(s) from which they were obtained. However, because Member G depositional regimes varied over time, lower Member G (Units G-1 to G-13, deposited in fluvial environments) was distinguished from upper Member G (Units G-14 to G-27, deposited in lacustrine environments) in some figures, following Bobe et al. (2002). Units G28 to H-7 are deltaic, and included as a separate grouping when appropriate. Sample sizes were unequal, ranging from 15 to 179 specimens per member. Statistically significant differences in mean astragalus size did not exist by member (ANOVA F-ratio 0.972, df=10, $p=0.467$ ), concordant with the argument for isotaphonomy through much of the sequence (Bobe et al., 2002). Overall, the DFA classified 12\% of the sample into the open category, $16 \%$ into light cover, 50\% into heavy cover, and 22\% into forest habitat. The fossil specimens were assigned to habitat preference categories with high probabilities. The mean probability of membership for Omo specimens assigned to the open habitat category was 
85\%, $78 \%$ for light cover, $87 \%$ for heavy cover, and $83 \%$ for the forest habitat category. The high probabilities of membership in all categories, and for modern and fossil specimens, give us confidence in the discriminatory power of the models.

Table 7 shows the distribution of astragali assigned to their habitat categories by member. Temporal midpoints are given for each member (from Bobe et al., 2002). The times between these midpoints ranged from $350 \mathrm{ka}$ to $50 \mathrm{ka}($ mean $=170 \mathrm{ka})$, so the time intervals represented by each member's deposition vary by a factor of seven. In order to examine time periods that were more equal in duration, the Shungura sequence was subdivided into shorter time periods sensu Bobe et al. (2002). These subintervals varied from $10 \mathrm{ka}$ to $210 \mathrm{ka}$, with a mean of $55 \mathrm{ka}$. Although subdividing the sample may provide a better approach to address time averaging and clearer temporal resolution, some of these subunits were very small both temporally and in terms of the number of specimens. Here, we limit our discussion to thirteen of these shorter intervals that have samples of 10 or more astragali (see Table 8 for all results by stratigraphic unit).

The proportions of all habitat preference ecomorphs fluctuated throughout the sequence (Figs. 3-5). Considering first the 4-habitat category model, the relative proportion of open habitat preferring bovids ranged from a low of 7\% in Members B and C, to a high of $19 \%$ in Member F. In fact, there was a trend of relatively high frequencies of open habitat preferring bovids in the later part of the sequence (Members D, E, F, and Upper G), which was interrupted by a relatively low frequency of $8 \%$ in Lower Member G. Light cover ecomorphs occurred with a low relative frequency of $10 \%$ in Member D and a high of $27 \%$ in Member B. Heavy cover ecomorphs were always dominant, varying from a low of $42 \%$ in Member F to a high of 60\% in Member C. Finally, forest ecomorphs were present throughout the sequence, with relative proportions ranging from 13\% in Member D to their highest proportion of 27\% in Lower Member G. Except in two instances, in Member E and Upper 
Member G, there was always a higher relative frequency of forest ecomorphs than of open habitat ecomorphs. In most of the Omo Shungura Members, the proportion of open habitat ecomorphs was relatively low, and frequently the smallest of the four categories present except in Members D and F, where it was the second least frequent category after the light cover ecomorphs.

We also classified the 401 astragali from Members B through $\mathrm{H}$ using the 5-habitat category model to determine the extent to which the wetlands ecomorph was represented in the different stratigraphic units. The results are shown in the bottom of Table 7. Overall, this method classified $11 \%$ of the sample into the open habitat category, $16 \%$ into light cover, $46 \%$ into heavy cover, $19 \%$ into forest, and $7 \%$ into the wetland category. The majority of the fossils attributed to the wetland category had been assigned to either heavy cover or forest by the 4-habitat model. When considering just Members B through Upper Member G ( $n=381)$, the wetland category was present in every member of the Shungura Formation except for Upper Member G, but was never abundant (Fig. 4). It represented a low relative abundance of $5 \%$ of the assemblage in Member $\mathrm{C}$, and its maximum extent was $10 \%$ of the assemblage in Member D (overall number of specimens ranged from one to 17). It is likely that the low frequencies of wetland habitat ecomorphs in the fossil sample are correct because this category had a high classification success rate.

We subdivided the sample into smaller temporal divisions for further analysis using the 4-habitat category model (Bobe et al., 2002). Bobe et al. (2002) used twenty intervals for their taxon-based paleoenvironmental analysis based on craniodental remains, but the sample of bovid astragali is too small to follow suit. Therefore we limited our analysis to 13 of these intervals that had at least ten astragali (Fig. 5). This subdivision enabled us to explore temporal variation at a finer scale, while maintaining reasonable sample sizes. Variation in relative ecomorph abundance was emphasized in these smaller samples. The open ecomorph 
varied in relative frequency from a low of $4 \%$ (in G6-8) to a high of 22\% (in E3-4). This was a greater range of relative frequency than observed in the by-member analysis. Similarly, the light cover ecomorphs ranged from a low of $0 \%$ in D4-5 to a high of $46 \%$ in B11-C4. Once again this was a much larger range of frequencies than shown when examining the data by member. Heavy cover ecomorphs, although still dominating all the interval assemblages except B11-C4 and E5-F1, also had a wider range of relative frequencies from 33\% (E5-F1) to $70 \%(\mathrm{G} 28-\mathrm{H} 7)$ of the interval assemblage. Forest ecomorphs were always present in these smaller intervals. Their relative proportions also fluctuated greatly, ranging from $5 \%$ of the G28-H7 interval assemblage to 44\% of the F4-G3 sample. The sample sizes per interval were too small to enable use of the 5-habitat category model on this time-constrained scale.

Body mass Six of the seven variables used for the DFA were correlated significantly with body size, using log femoral length as a body size proxy (Table 9; adjusted $\mathrm{R}^{2}$ ranging from 0.21-0.97; $\mathrm{p}<0.001)$. Only the variable LDEPRA9 was not significantly correlated with femoral length $\left(R^{2}=0.0003 ; p=0.8100\right)$. We examined the size distribution of our sample of modern and fossil bovid astragali across the different habitat preference categories using LMINLEN as a proxy for body mass (Fig. 8). Comparing the modern and fossil size distributions makes it clear that very small bovids, which in the modern sample are predominantly in the light cover and forest preferring categories, are under-represented in the Omo collection. This may signal that these ecomorphs were under-represented due to a size related taphonomic or collection bias. Modern astragali attributed to the open and heavy cover categories largely overlap with each other in terms of size, and one would expect a great deal of misclassifications between these groups, and between light cover and forest, if body mass was driving the DFA results. Moreover, a number of fossils assigned to forest actually extend beyond the size range of forest bovids in the extant sample used in the DFA 
model (Fig. 8). This is a further indication that body size alone is not driving the habitat attribution of fossils.

\section{Discussion}

The high overall success rates of our models allow us to have confidence in the habitat preference assignments predicted for the Omo fossil sample. This is a critical starting point when investigating shifts in the relative proportions of ecomorphs through time (Plummer et al., 2008). Given that much of the sequence is isotaphonomic, shifts in ecomorph proportions should, at some level, reflect shifts in the relative proportions of habitats existing in the vicinity of the paleo-Omo River (or lake, in upper Member G) (Bobe et al., 2002). Here we use the results of our ecomorphic analyses to assess observations made by previous taxon-based analyses of fauna, paleobotanical remains, sedimentological analyses and isotopic studies (e.g., Bobe and Eck, 2001; Bobe et al., 2002; Alemseged, 2003; Bobe and Behrensmeyer, 2004; Bobe, 2006; Bobe et al., 2007; Bobe and Leakey, 2009; Bobe, 2011; Levin et al., 2011; see Fig. 9).

Our ecomorph data are consistent with our first prediction that a spectrum of habitats existed through time in the Shungura Formation sequence, with a relatively high representation of woodland and forest habitats. A range of ecomorphs was found in the fossil sample, but ecomorphs representing wooded contexts (woodlands and forest) were particularly well represented (Figs. 3-5, 9). Moreover, it is likely that the forest and light cover ecomorphs were actually underrepresented. In attritional assemblages formed in past and present African ecosystems there is frequently a strong bias against small $(<15 \mathrm{~kg})$ mammal taxa, such that their frequency in death assemblages is often lower than their frequency in living communities (Behrensmeyer and Dechant Boaz, 1980, Potts, 1988; Behrensmeyer and Chapman, 1993). The Omo 
sample lacks the small (size 1) bovids that are found in the modern forest and light cover samples (Fig. 8), most likely because of a taphonomic bias against this size class, and so these habitats may be underrepresented by the ecomorph proportions presented here.

The heavy cover category, here interpreted as heavy bushland or woodland, was particularly well represented throughout the sequence. Our past models (e.g., Plummer and Bishop, 1994; Plummer et al., 2008; Bishop et al., 2011, Louys et al., 2013), and the models of other researchers (e.g., Kappelman et al., 1997; DeGusta and Vrba, 2003) conflate bovids preferring wetlands with those preferring woodlands within the heavy cover category. At many paleontological sites, where wetlands can be effectively ruled out by sedimentological analysis or other proxies, this is probably not a problem. The Shungura Formation has clear evidence of wetland environments however, both sedimentologically and in the form of Typha pollen, so it is potentially important not to conflate woodland with wetland habitats here (Bobe and Eck, 2001). Our 5-habitat model suggests that wetland ecomorphs were present, but did not make up a substantial percentage of the overall bovid sample $(<10 \%$ in every member; see Table 7, Fig. 4). The strong heavy cover signal in both the 4- and 5habitat models almost certainly reflects woodland rather than wetlands.

Data from this study are equivocal on our second prediction, whether an environmental shift occurred at approximately 2.8 Ma (between Members B and C), which resulted primarily in a shift from wet, closed environments to dry, closed environments. A range of environmental proxies suggests there was a transition from wet and closed environments to dry and closed environments at approximately 2.8 Ma (between Members B and C) (Bobe and Behrensmeyer, 2004; Bibi et al., 2013). There was no significant shift in ecomorph frequency from Member B to Member C using either the 4- or 5-category model, especially when compared with the taxonomically-based rodent and bovid data (Fig. 9). At the finer scale, there is a strong shift in the proportions of light cover and heavy cover 
ecomorphs between interval B11-C4 and interval C6-7 (Fig. 5). Light cover strongly dominates the earlier interval, and this shifts to heavy cover dominance in C6-7 (from $46 \%$ light cover and $38 \%$ heavy cover to $19 \%$ and $63 \%$, respectively). The relative proportions of open and forest ecomorphs show less change between B11-C4 and interval C6-7.

Our data are consistent with our third prediction that there was an interval of relative environmental stability from 2.7-2.5 Ma, followed by an increase in habitat variability between 2.5 - 2.0 Ma (Figs. 5, 9). The two intervals (C6-7, C8) that fall between 2.7 and 2.5 Ma are relatively similar (6\% open,19\% light cover, 63\% heavy cover, $13 \%$ forest versus $7 \%$ open,11\% light cover, $63 \%$ heavy cover, $19 \%$ forest, variation in frequencies $0 \%-8 \%$ ) whereas those that follow between $2.5-2.0$ (intervals between D4-5 and G14-27) are quite variable, particularly in the frequency of open, light cover, and forest ecomorphs (range of variation for open 18\%, light cover $30 \%$, heavy cover $31 \%$ and forest $37 \%$ ). However, the sample sizes are unequal, and time spans are unequal and discontinuous, so it is possible that results reflect varying temporal scales rather than a discrete paleoenvironmental trend.

From our analysis, there was an increase in open habitat ecomorphs from Members C to F (Figs. 3, 4, 9). This is consistent with an expansion of secondary grassland as reflected in pollen, rodent and bovid taxonomic abundance data. This may be related to aridification and consistent with our fourth prediction that a drying trend existed between Members $\mathrm{C}$ and F or simply result from landscape remodelling or soil change, for example by the deposition of a volcanic tuff. Figure 5 shows that the samples from Members D and E had higher proportions of open habitat ecomorphs than the lower $G$ units, though there was some fluctuation, with Unit G4 having a relatively high open ecomorph frequency. However, the proportion of forest ecomorphs also increased between Members C and D and can be seen to 
fluctuate throughout the sequence. This suggests that any drying trend did not decrease the availability of forest as grassland increased. This could be due to a variety of geographical causes, such as the persistence of gallery forest alongside the paleo-Omo River.

Our results do not support the fifth prediction that taxa associated with grasslands became more common than those associated with forest after $2.5 \mathrm{Ma}$, with a small peak in taxa preferring relatively open environments in Member F at approximately 2.35 Ma. There were times (e.g., Member E, Figs. 3, 4, 9) where open ecomorphs were more common than forest ones, but the opposite was true for Members D, F, and Lower Member G. The more refined stratigraphic intervals show a great deal of fluctuation in open and forest ecomorphs, with the forest ecomorphs (e.g., F4-G3, G6-G8) sometimes being considerably more common than the open ones (Fig. 5). Further, as mentioned above, the increase in relative frequency of open ecomorphs did not occur universally at the expense of forest ecomorphs. Although our data show that the highest relative proportion of open ecomorphs occurred during Member F, this does not represent a strong, outlying peak to the relative frequency of open habitats. Instead our data examined by member show a gradual increase in the relative proportion of open ecomorphs peaking at 19\% during Member F. When examined by interval, however, the apparent pattern is more complex. The biggest jump in relative frequency of open ecomorphs occurred between C8 and D4-5, when it changed from 7\% to $20 \%$. However, these intervals were not continuous so the increased frequency might have been attained more gradually than it appears. The relatively high proportion of open ecomorphs then persisted for 3 intervals (D4-5, E3-4, and E5-F1) before dropping to 8\% in interval F4-G3. There was no evidence for a peak in open country bovids in lower Member F, rather a more sustained plateau of relatively high frequencies between D4-5, E3-4, and E5-F1 (Fig. 5). Subsequently, open ecomorphs jumped to $21 \%$ of the overall sample in G4. The relative frequencies of forest ecomorphs also fluctuated, although the patterns evinced appear 
to bear no consistent relation, either positive or negative, with the changes in relative frequencies of open ecomorphs. The changes in relative frequency of open ecomorphs were more extreme in these smaller, discontinuous intervals, ranging from $4-22 \%$. However, it is more difficult to discern patterns and trends in these data than it is for the samples examined by member.

Our data are consistent with our sixth prediction that grassland-dominated habitats expanded during upper Member G deposition, and thereafter, with some fluctuation, made up a greater proportion of the overall environment than they had prior to lower Member G. The relative proportion of open habitat ecomorphs increases from lower to upper G (Figs. 3, 4). This is also borne out by the finer temporal intervals from G14-27 to G28-H7 (Fig. 5, Table 8). Our sample from Members $J$ through $L$ is small $(n=11)$, but the frequency of ecomorphs in this sample is similar to that of G28-H7 at 18\%. However, there are intervals with high open habitat ecomorph frequencies prior to lower Member G, suggesting that a more finely resolved record might show some relatively high intervals of open ecomorph representation earlier in time.

Predictions five and six were based on the analysis of multiple macromammalian taxa, as well as microfauna, paleobotanical data, and stable isotopes (e.g., Bobe and Eck, 2001; Bobe and Behrensmeyer, 2004; Levin et al., 2011). Bobe et al. (2007) used the proportion of Alcelaphini-Antilopini-Hippotragini (AAH) bovids out of the total number of specimens identified to tribe as an additional proxy indicating grassy habitats (Table 10). Modern game reserves that have high AAH frequencies tend to have a large proportion of open habitats, whereas those with low AAH frequencies do not (Vrba, 1980; Bobe, 2006). Our analysis shows that the relative proportion of open habitat ecomorphs increased steadily from $7 \%$ in Member C to $19 \%$ in Member $\mathrm{F}$. This is a stronger signal for a drying trend than is provided by the AAH using bovids attributed to tribe (Bobe et al., 2007). Because the by- 
member fossil samples are relatively isotaphonomic (Bobe et al., 2002), the frequencies of cranial parts identifiable to taxon and astragali remained reasonably uniform over time (see Bobe et al., 2002). It is therefore unlikely that this discrepancy between the AAH and open ecomorph frequencies is related to taphonomic variations affecting the relationship between cranial and postcranial elements over time. The AAH oscillated between $2.6 \%$ and $8.8 \%$ without demonstrating a clear directional trend. In this case the ecomorph data provide an improved ability to register changes in relative habitat abundance and mirror trends shown in a variety of environmental proxies, for example paleobotanical and microfaunal data (Bobe and Eck, 2001; Alemseged, 2003; Fig. 9).

\section{Ecomorph variability and hominin paleoenvironments}

The relative rarity of hominin fossils in the Shungura Formation suggests they were not particularly abundant in their paleocommunities. This is best assessed by examining the frequency of hominin fossils occurring in the samples of the skeletal parts (astragali and mandibles) that were systematically collected by the American Omo Expedition for all taxa (Bobe and Eck 2001; Bobe and Leakey, 2009). Eck’s team recovered 601 astragali and 773 mandibles from all mammals. While none of the astragali was hominin, 5 of the mandibles were, demonstrating an overall abundance of $0.65 \%$ for the mandible assemblage. Theropithecus, which is similar in body size and overall skeletal morphology to hominins, is much more abundant in the mandible sample, $(n=96,12.4 \%)$. These abundances suggest that hominins were rare in the Omo paleolandscape, even relative to some other primates.

Three hominin genera, Australopithecus, Paranthropus and Homo, are known from the Shungura Formation, and most of these are found in deposits below Unit G5 in Lower Member G (Bobe et al., 2002; Alemseged, 2003; Bobe and Behrensmeyer, 2004; Bobe and 
Leakey, 2009). Specimens attributable to Australopithecus are known from Members B to D, from about 3.2 to 2.4 Ma (Fig. 3). Paranthropus first appears in Member C at about 2.7 Ma, and Homo first appears in Member E at about 2.4 Ma. The specific habitat preferences of individual hominin taxa, and the degree to which these habitat preferences differed, is difficult to determine. Paleoenvironmental analysis at the level of member suggests that all three genera were associated with environments containing a broad range of habitats (forest to grassland), with wooded settings being particularly common (Fig. 3). AAH values by member are all low, indicating that secondary grasslands were not particularly extensive (Table 10). Several statistical associations have been made between hominin genera and other faunal elements in the paleocommunities (Bobe and Behrensmeyer, 2004). Australopithecus is significantly associated with the suid Kolpochoerus heseloni (= K. limnetes), which preferred well-wooded to mixed habitats, and had a diet that varied from mixed C3/C4 to a variable grazing $\mathrm{C} 4 \operatorname{diet}\left(\delta^{13} \mathrm{C}-6.3\right.$ to 1.4$)$ (Bishop et al., 2006). Australopithecus is also strongly associated with the colobine Rhinocolobus turkanaensis, whose preference for woodlands and folivorous diet is an indicator of well-wooded settings (Bobe and Behrensmeyer, 2004). In Members E to lower G, Paranthropus is strongly associated with Theropithecus oswaldi, which preferred grassy settings, and with Homo. Homo, in turn, is associated with Papio, thought to be a habitat and dietary generalist, as well as with the bovid Tragelaphus gaudryi, thought to prefer bushy habitats. The finding that Paranthropus and Homo had strong associations with different taxa, at the same time that Paranthropus was strongly associated with Homo, may indicate that there were but subtle habitat preference differences between these genera during Shungura Formation deposition. 
When the ecomorph abundance data are grouped by member, Australopithecus is predominantly associated with lower frequencies of open habitat ecomorphs, and high frequencies of heavy cover ecomorphs (Fig. 3). Perhaps, as indicated by its association with R. turkanaensis and Kolpochoerus heseloni (= K. limnetes),, this reflects a more woodland focus for its activities. Homo and Paranthropus are found in paleoenvironmental settings that include both very low open ecomorph frequencies (Lower G) as well as relatively higher open ecomorph frequencies (Members E and F) (Fig. 3). When assessed by the shorter stratigraphic intervals, the predominantly heavy cover association for Australopithecus is still apparent, though the relatively small ( $n=10)$ D4-5 interval has a higher open ecomorph frequency than the larger C8 sample ( $n=27)$ that precedes it (Fig. 5). Paranthropus and Homo are both associated with varied environments that still contain relatively high frequencies of open and often of light cover ecomorphs. Homo occurs with a higher proportion of open ecomorphs in the by-member analysis, but this is not as evident in the interval analysis. Homo fossils are not uniquely associated with the intervals where open ecomorphs are at their highest (G28-H7 no hominins, G4 Paranthropus only). Alternatively, the association of Paranthropus and Homo with habitat spectra containing slightly higher proportions of open and light cover ecomorphs could reflect a gradual drying trend through time (see observation 4 above) independent of habitat preference differences between earlier (Australopithecus) and later (Paranthropus and Homo) hominin taxa.

\section{Summary and conclusions}

The bovid astragalus is a commonly preserved bone in the fossil and archaeological records. Here we provide astragalus DFA models that offer a good compromise between application to fragmentary fossil specimens, and high classification success rates. Seven 
variable DFA models were developed to assign fossil bovid astragali to habitat categories ranging from open cover to forest, with a wetland category being created for one model. Analysis of divergence and convergence within our bovid sample relative to phylogeny confirms that our models conform to an ecomorphic framework. The accuracy of these models is high (>82 \%) as assessed by resubstitution and jackknife analyses, and they provide a useful method for predicting the habitat preferences of unassigned astragali from the Omo Shungura Formation.

Analysis of the Shungura Formation fauna demonstrated an abundance of heavy cover ecomorphs, and a trend of increasing open ecomorph frequencies through time between Members C and F. Our 5-habitat category model demonstrated that although Typha pollen and sedimentological indicators of near-water paleoenvironments existed, wetland ecomorphs were never very common. Our results are also notable in demonstrating that, although there were fluctuations between the relative abundance of different habitat preference ecomorphs through time, each ecomorph type was always present. Using ecomorph abundance as a proxy for habitat availability, we conclude that Omo vegetational environments were consistently heterogenous through time. Even at times that other proxies suggested were the driest during Shungura Formation deposition, woodland and forest ecomorphs persisted, sometimes at relatively high frequencies.

Hominin fossils attributed to Australopithecus, Paranthropus, and Homo have been recovered from Shungura Formation deposits. When the ecomorph abundance data are grouped by member, Australopithecus is predominantly associated with lower frequencies of open habitat ecomorphs, and higher frequencies of heavy cover ecomorphs (Fig. 3). Homo and Paranthropus are found in paleoenvironmental settings that include both very low open ecomorph frequencies (Lower $G$ ) as well as relatively high open ecomorph frequencies (Members E and F) (Fig. 3). This seems to support the suggestion that Homo and 
Paranthropus preferred, or perhaps simply had greater access to, a more heterogeneous mix of environments including more open and light cover habitats (sensu Bobe and Behrensmeyer, 2004).

The development of ecomorphic methods using a broad array of taxa and skeletal elements will ultimately help mitigate data lost by the differential destruction of particular elements or element portions by density-mediated processes, such as carnivore consumption (Faith and Behrensmeyer, 2006). Larger samples of fossils amenable to analysis will allow more robust comparisons between different types of ecomorphic analyses, such as postcranial ecomorphology and ecomorphic assessments of community structure. Future ecomorphic research in the lower Omo Valley and Turkana basin could productively extend the work described here. The analysis of additional postcranial elements from the Shungura Formation samples would increase the sample of ecomorphs per member, and ultimately could provide large enough samples to look at shifts in ecomorph frequencies over much more refined (submember to unit) time intervals. Improved sampling would also allow ecomorphic analysis to be carried out by collection area or locality, to address horizontal variation in ecomorph frequencies across the areas the Shungura Formation is exposed, and to look specifically at the ecomorphic signal associated with hominin finds. With a higher level of resolution and better correlation across proxy records, changes in ecomorph frequencies could be assessed relative to local, regional, and global climatic fluctuations. Finally, it would be interesting to extend the ecomorphic analysis to the Nachukui and Koobi Fora Formations on the west and east sides, respectively of Lake Turkana. Stable isotopic analysis of paleosol carbonates from the Omo Group suggested that the Shungura Formation was dominated by C3 vegetation (e.g., bushes and trees), whereas the coeval deposits of the Koobi Fora and Nachukui Formations had a greater proportion of C4 (grassy) vegetation 
(Levin et al., 2011). We predict that this variation in C4 vegetation between different formations of the Omo Group will translate into parallel differences in ecomorph

\section{Acknowledgements}

We thank the curators and staff of the mammal collections at the American Museum of Natural History (New York, NY), the National Museum of Natural History (Washington, DC) and the Natural History Museum (London). LCB acknowledges funding from The Leverhulme Trust. FH thanks the CSUN Office of Research and Sponsored Projects. JL is funded by Australian Research Council Laureate grant FL120100156. We thank Neil Jones for assistance in preparing the figures, and the editor, associate editor, and two anonymous reviewers for their constructive criticism. 


\section{References}

Alemseged, Z., 2003. An integrated approach to taphonomy and faunal change in the Shungura Formation (Ethiopia) and its implication for hominid evolution. J. Hum. Evol. 44, $1-28$.

Andrews, P., Lord, J., Evans, E.M.N., 1979. Patterns of ecological diversity in fossil and modern mammalian faunas. Biol. J. of the Linn. Soc. 11, 177-205.

Arambourg, C., 1947. Mission scientifique de l’Omo (1932-1933). Vol. 1. GéologieAnthropologie, fasc. 3, pp. 231-562. Memoire, Muséum national d’histoire naturelle (Paris).

Barr, W.A., 2014. Functional morphology of the bovid astragalus in relation to habitat: controlling phylogenetic signal in ecomorphology. J. Morphol. 275, 1201-1216.

Barr, W., Scott, R., 2013. Phylogenetic comparative methods complement discriminant function analysis in ecomorphology. Am. J. Phys. Anthropol. 153, 663-674.

Behrensmeyer, A.K., Chapman, R.E., 1993. Models and simulations of taphonomic timeaveraging in terrestrial vertebrate assemblages. In: Kidwell, S.M., Behrensmeyer, A.K. (Eds.), Taphonomic Approaches to Time Resolution in Fossil Assemblages. [Short Courses in Paleontology Number 6]. The Paleontological Society, Knoxville, Tennessee, pp. 125-149. 
Behrensmeyer, A. K., Dechant, D.E., 1980. The recent bones of Amboseli Park, Kenya in relation to East African paleoecology. In: Behrensmeyer, A.K., Hill, A. (Eds.), Fossils in the Making. University of Chicago Press, Chicago, pp. 72-93.

Bibi, F., Souron, A., Bocherens, H., Uno, K., Boisserie, J. R., 2013. Ecological change in the lower Omo Valley around 2.8 Ma. Biology Letters, 9(1), 20120890.

Bishop, L.C., King, T., Hill, A., Wood, B., 2006. Palaeoecology of Kolpochoerus heseloni (= K. limnetes): a multiproxy approach. T. Roy. Soc. S. Afr.61 (2): 81-88.

Bishop, L.C., Plummer, T.W., Hertel, F., Kovarovic, K., 2011. Paleoenvironments of Laetoli, Tanzania as determined by antelope habitat preferences. In: Harrison, T. (Ed.), Paleontology and Geology of Laetoli: Human Evolution in Context. Vol. 2: Fossil Hominins and the Associated Fauna. Springer, Dordrecht, pp. 355-366.

Bobe, R., 2006. The evolution of arid ecosystems in eastern Africa. J. Arid Environ. 66(3), 564-584.

Bobe, R., 2011. Fossil mammals and paleoenvironments in the Omo-Turkana Basin. Evol. Anthropol. 20(6), 254-263.

Bobe, R., Eck, G.G., 2001. Responses of African bovids to Pliocene climatic change. Paleobiol. 27, 1-47. 
Bobe, R., Behrensmeyer, A.K., 2004. The expansion of grassland ecosystems in Africa in relation to mammalian evolution and the origin of the genus Homo. Palaeogeog. Palaeoclimatol. Palaeoecol. 207, 399-420.

Bobe, R., Leakey, M.G., 2009. Ecology of Plio-Pleistocene mammals in the Omo-Turkana Basin and the emergence of Homo. In: Grine, F.E., Fleagle, J.G., Leakey, R.E. (Eds.), The First Humans: Origins of the Genus Homo, Springer, Dordrecht pp. 173-184.

Bobe, R., Behrensmeyer, A.K., Chapman, R., 2002. Faunal change, environmental variability and late Pliocene hominin evolution. J. Hum. Evol. 42, 475-497.

Bobe, R., Behrensmeyer, A.K., Eck, G.G., Harris, J.M., 2007. Patterns of abundance and diversity in late Cenozoic bovids from the Turkana and Hadar Basins, Kenya and Ethiopia. In: Bobe, R., Alemseged, Z., Behrensmeyer, A.K., (Eds.), Hominin Environments in the East African Pliocene: An Assessment of the Faunal Evidence, Springer, Dordrecht, pp. 129-157.

Bonnefille, R., Dechamps, R.,1983. Data on fossil flora. Ann. Mus. Roy. Afr. Centr., Tervuren, Sci. gGeol, 85, 191-207.

DeGusta, D., Vrba, E.S., 2003. A method for inferring paleohabitats from the functional morphology of bovid astragali. J. Archaeol. Sci. 30, 1009-1022.

Estes, R.D., 1991. The Behavior Guide to African Mammals. University of California Press, Berkeley. 
Faith, J.T., Behrensmeyer, A.K., 2006. Changing patterns of carnivore modification in a landscape bone assemblage, Amboseli Park, Kenya. J. Archaeol. Sci. 33, 1718-1733.

Gentry, A.W., 1970. The Bovidae (Mammalia) of the Fort Ternan fossil fauna. In: Maglio, V.J., Cooke, H.B.S., (Eds.), Fossil Vertebrates of Africa. Vol. 2, Academic Press, London, pp. 243-323.

Hammer, Ø., Harper, D.A.T., Ryan, P.D., 2001. PAST: Paleontological Statistics Software Package for Education and Data Analysis. Palaeontol. Electron. 4(1), 1-9.

Hernández Fernández, M., Vrba, E.S., 2005. A complete estimate of the phylogenetic relationships in Ruminantia: A dated species-level supertree of the extant ruminants. Biol. Rev. Cam. Philos. Soc. 80, 269-302.

Hertel, F., 1995. Ecomorphological indicators of feeding behaviour in recent and fossil raptors. Auk 112, 890-903.

Hildebrand, M., Goslow, T., 2001. Analysis of Vertebrate Structure, fifth ed. John Wiley and Sons, New York.

James, M., 1985. Classification Algorithms. John Wiley and Sons, New York.

Kappelman, J., 1986. The paleoecology and chronology of the Middle Miocene hominoids from the Chinji Formation of Pakistan. Ph.D. Dissertation, Harvard University. 
Kappelman, J., 1988. Morphology and locomotor adaptations of the bovid femur in relation to habitat. J. Morphol. 198, 119-130.

Kappelman, J., 1991. The paleoenvironment of Kenyapithecus at Fort Ternan. J. Hum. Evol. 20, 95-129.

Kappelman, J., Plummer, T.W., Bishop, L.C., Duncan, A., Appleton, S., 1997. Bovids as indicators of Plio-Pleistocene paleoenvironments of East Africa. J. Hum. Evol. 32, 95-129.

Klein, R.G., Franciscus, R.G., Steele, T.E., 2010. Morphometric identification of bovid metapodials to genus and implications for taxon-free habitat reconstruction. J. Archaeol. Sci. 37, 389-401.

Köhler, M., 1993. Skeleton and habitat of recent and fossil ruminants. Münchner Geowissenschaftliche Abhandlungen 25, 1-88.

Kovarovic, K., Andrews, P., 2007. Bovid postcranial ecomorphological survey of the Laetoli paleoenvironment. J. Hum. Evol. 52, 663-680.

Kovarovic, K., Aiello, L.C., Cardini, A., Lockwood, C.A., 2011. Discriminant function analyses in archaeology: Are classification rates too good to be true? J. Archaeol. Sci. 38, 3006-3018. 
Levin, N.E., Brown, F.H., Behrensmeyer, A.K., Bobe, R., Cerling, T.E., 2011. Paleosol carbonates from the Omo Group: Isotopic records of local and regional environmental change in East Africa. Palaeogeog. Palaeoclimatol. Palaeoecol. 307, 75-89.

Louys, J., Montanari, S., Plummer, T., Hertel, F., Bishop, L.C., 2013. Evolutionary divergence and convergence in shape and size within African antelope proximal phalanges. J. Mamm. Evol. 20, 239-248.

Louys, J., Meloro, C., Elton, S., Ditchfield, P., Bishop, L.C., 2015. Analytical framework for reconstructing heterogeneous environmental variables from mammal community structure. J. Hum. Evol. 78, 1-11.

Meloro, C., Elton, S., Louys, J.C., Bishop, L.C., Ditchfield, P., 2013. Cats in the forest: predicting habitat adaptations from humerus morphometry in extant and fossil Felidae (Carnivora). Paleobiol. 39(3), 323-344.

Plummer, T.W., Bishop, L.C., 1994. Hominid paleoecology at Olduvai Gorge, Tanzania as indicated by antelope remains. J. Hum. Evol. 29, 321-362.

Plummer, T.W., Bishop, L.C., Hertel, F. 2008. Habitat preference of extant African bovids based on astragalus morphology: operationalizing ecomorphology for palaeoenvironmental reconstruction. J. Archaeol. Sci. 35, 3016-3027.

Potts, R., 1988. Early Hominid Activities at Olduvai. Aldine De Gruyter, New York. 
Reed, K.E., 1997. Early hominid evolution and ecological change through the African PlioPleistocene. J. Hum. Evol. 32, 289-322.

Reyment, R.A., 1991. Multidimensional Paleobiology. Pergamon Press, New York.

Scott, K.M., 1979. Adaptation and Allometry in Bovid Postcranial Proportions. Ph.D.

Dissertation. Yale University.

Scott, K., 1985. Allometric trends and locomotor adaptations in the Bovidae. Bull. Am. Mus. Nat. Hist. 197, 197-288.

Scott, R.S., Barr, W.A., 2014. Ecomorphology and phylogenetic risk: implications for habitat reconstruction using fossil bovids. J. Hum. Evol. 73, 47-57.

Vrba, E.S. 1980. The significance of bovid remains as indicators of environment and predation patterns. In: Behrensmeyer, A.K., Hill, A.P. (Eds.), Fossils in the Making, University of Chicago Press, Chicago, pp. 247-271

Walmsley, A., Elton, S., Louys, J., Bishop, L.C., Meloro, C., 2012. Humeral epiphyseal shape in the Felidae: The influence of phylogeny, allometry, and locomotion. J. Morph. 273(12), 1424-1438. 


\section{Figure captions:}

Figure 1. Location of the Shungura Formation within the Omo-Turkana Basin (after Bobe 2011, Fig. 1).

Figure 2. Caliper measurements used in this study, illustrated on bovid left astragalus. Superior view, a. Medial view, b. For descriptions of these measurements, see Table 2.

Figure 3. Results of discriminant function analysis of Omo Shungura Formation astragali using the 4-habitat category discriminant function model. The relative frequencies of each habitat preference ecomorph are shown for individual stratigraphic members within each bar. The number of fossils assigned to each category is shown within the bars. The occurrences of hominin taxa in each member (Bobe et al., 2002) are indicated by the letters above each bar, with $\mathrm{A}=$ Australopithecus, $\mathrm{P}=$ Paranthropus and $\mathrm{H}=$ Homo.

Figure 4. Results of discriminant function analysis of Omo Shungura Formation astragali using the 5-habitat category discriminant function model. The relative frequencies of each habitat preference ecomorph are shown for individual stratigraphic members within each bar. The number of fossils assigned to each category is shown within the bars.

Figure 5. Results of discriminant function analysis of Omo Shungura Formation astragali using the 4- category discriminant function model. The relative frequencies of each habitat preference ecomorph are shown for individual stratigraphic intervals (as defined by Bobe et al., 2002) where sample sizes were 10 or more astragali. Raw sample sizes for each category are shown within the bars. The occurrences of hominin taxa in each interval (Bobe et al., 
2002) are indicated by the letters above each bar, with A denoting Australopithecus, $\mathrm{P}=$ Paranthropus and $\mathrm{H}=$ Homo.

Figure 6. Notched box plots summarizing the range of canonical scores for each habitat group; a, b, c are the canonical scores for the 4-habitat model and d, e, f, and g are those for the 5-habitat model. The horizontal line at the point of constriction of each box represents the sample median. The upper and lower margins of the boxed areas are termed hinges. The median divides the sample distribution in halves, whereas the hinges split the halves into quarters. The outer confidence limits are encompassed by each box. If the notched areas of two samples do not overlap, there is a high probability (95\% or higher) that the samples in question were drawn from different populations.

Figure 7. Box plots of the Euclidian distances between each potential species pair for externally ordinated morphospace, a: 4-habitat model, b: 5-habitat model. Species classified according to level of relatedness between species pairs, derived from Hernández Fernández and Vrba (2005). The mean divergence time for congeneric African Bovidae was 4.59 Ma, with a standard deviation of 2.94 Ma calculated using data from Hernández Fernández and Vrba (2005). Two species were considered closely related if their time since divergence was less than $11 \mathrm{Ma}$, representing the mean divergence time + two standard deviations. Environments were represented by the habitat classifications of open, light cover, heavy cover, forest and, in the 5-category model, wetland. For each group, the 25-75 percent quartiles are drawn using the box, the median is shown with a horizontal bar in the box, the whiskers accompanying the box show minimum and maximum values, and outliers are shown as points. Asterisks indicate significant differences $(p \leq 0.05)$ between the groups for both models. 
Figure 8. LMINLEN (log minimum length of the astragalus, a proxy for body size) versus habitat category is shown for (a) modern astragali in this study and (b) Shungura Formation fossil antelope astragali analysed with the 4-habitat DFA. The modern astragali exhibit a wider range of LMINLEN values, including small values not found in the fossil sample. In addition, the range of LMINLEN in the Shungura Formation sample extends beyond what is seen in the modern forest habitat category. On the y-axis, 1=open, 2=light cover, 3=heavy cover, $4=$ forest.

Figure 9. A summary of select paleoenvironmental indicators, juxtaposed against Shungura Formation geochronology and stratigraphy. (a) Chronology and stratigraphy. (b) Depositional environments and paleosols. (c) Paleobotanical evidence (C/A\% = percentage of Chenopodiaceae/Amaranthaceae). (d) Micromammals. (e) Shungura environments based on bovid abundances. (f) Ecomorph frequencies for the 4-habitat model described here. After Bobe and Eck (2001), Fig. 3. 
Table 1. Taxon list, sample size, and habitat preference category for specimens used in this analysis.

\section{Subfamily}

Tribe

Bovinae

Antilopinae

Hippotraginae

\section{Reduncini}

Hippotragini

Alcelaphinae

\section{Aepycerotini}

Alcelaphini

Antidorcas marsupialis
Gazella granti
Gazella thomsoni

Tragelaphus euryceros

Tragelaphus imberbis

Tragelaphus scriptus

Tragelaphus spekei

Tragelaphus strepsiceros

Cephalophus dorsalis

Cephalophus leucogaster

Cephalophus monticola

Cephalophus natalensis

Cephalophus nigrifrons

Cephalophus silvicultor

Cephalophus weynsi

Sylvicapra grimmia

Madoqua kirkii
Neotragus moschatus
Ourebia ourebia
Raphicerus campestris

Raphicerus campestris

Gazella thomsoni

Kobus ellipsiprymnus
Kobus kob
Kobus megaceros
Kobus leche
Redunca redunca
Redunca arundinum
Redunca fulvorufula
Addax nasomaculatus
Hippotragus equinus
Hippotragus niger
Oryx gazella

Aepyceros melampus

\section{$\underline{\text { Sample } \quad \text { Habitat }}$ size}

$\begin{array}{cl}6 & \text { Heavy cover } \\ 4 & \text { Heavy cover } \\ 17 & \text { Forest } \\ 11 & \text { Wetland } \\ 7 & \text { Heavy cover }\end{array}$

$\begin{array}{cl}5 & \text { Forest } \\ 4 & \text { Forest } \\ 4 & \text { Forest } \\ 4 & \text { Forest } \\ 4 & \text { Forest } \\ 7 & \text { Forest } \\ 5 & \text { Forest } \\ 17 & \text { Light Cover }\end{array}$

11 Light Cover

4 Forest

7 Light Cover

5 Light Cover

$\begin{array}{cc}8 & \text { Open } \\ 10 & \text { Open } \\ 8 & \text { Open }\end{array}$

10 Heavy Cover

10 Light Cover

7 Wetland

1 Wetland

10 Light Cover

7 Light Cover

8 Light Cover

$\begin{array}{cc}4 & \text { Open } \\ 4 & \text { Open } \\ 9 & \text { Open } \\ 13 & \text { Open }\end{array}$

12 Light Cover

$\begin{array}{lcl}\text { Alcelaphus buselaphus } & 14 & \text { Open } \\ \text { Connochaetes gnou } & 5 & \text { Open } \\ \text { Connochaetes taurinus } & 6 & \text { Open } \\ \text { Damaliscus dorcas } & 8 & \text { Open } \\ \text { Damaliscus lunatus } & 10 & \text { Open }\end{array}$


Table 2. Variables used in the analyses, illustrated in Figure 2.

\begin{tabular}{|c|c|c|}
\hline $\begin{array}{l}\text { Variable } \\
\text { name }\end{array}$ & Variable Type & Description \\
\hline TARSMLT & measurement & Mediolateral dimension of the tarsal articulation \\
\hline TAMAP & measurement & $\begin{array}{l}\text { Anterioposterior dimension of the medial side of the tarsal } \\
\text { articulation }\end{array}$ \\
\hline MINLEN & measurement & $\begin{array}{l}\text { Minimum length of the astragalus, measured from the central } \\
\text { depressions of each trochlea }\end{array}$ \\
\hline LENRA8 & ratio & $\begin{array}{l}\text { Medial length of the astragalus (MEDLEN) divided by the minimum } \\
\text { breadth of the tarsal articulation (FOFO) }\end{array}$ \\
\hline LENRA21 & ratio & $\begin{array}{l}\text { Medial length of the astragalus (MEDLEN) divided by the trochlear } \\
\text { diameter of the medial side of the tibial articulation (TIMAP) }\end{array}$ \\
\hline LMLRAT3 & ratio & $\begin{array}{l}\text { Maximum mediolateral dimension of the astralagus (TUBML) divided } \\
\text { by the minimum breadth of the tarsal articulation (FOFO) }\end{array}$ \\
\hline DEPRA9 & ratio & $\begin{array}{l}\text { Mediolateral dimension of the tarsal articulation (TARSMLT) divided } \\
\text { by the maximum depth of the astragalus (MAXSI) }\end{array}$ \\
\hline
\end{tabular}


Table 3. Summary statistics of $\log _{10}$-transformed variables used in the quadratic discriminant function models.

\begin{tabular}{|c|c|c|c|c|c|}
\hline \multicolumn{6}{|l|}{ LTARSMLT } \\
\hline Open & 99 & 1.439 & 0.115 & 1.152 & 1.638 \\
\hline Light cover & 87 & 1.232 & 0.137 & 0.907 & 1.439 \\
\hline Heavy cover & 27 & 1.542 & 0.060 & 1.362 & 1.613 \\
\hline Forest & 54 & 1.222 & 0.140 & 0.924 & 1.428 \\
\hline Wetland & 19 & 1.420 & 0.026 & 1.384 & 1.471 \\
\hline \multicolumn{6}{|l|}{ LTAMAP } \\
\hline Open & 99 & 1.347 & 0.107 & 1.069 & 1.539 \\
\hline Light cover & 87 & 1.136 & 0.139 & 0.797 & 1.353 \\
\hline Heavy cover & 27 & 1.418 & 0.052 & 1.252 & 1.495 \\
\hline Forest & 54 & 1.087 & 0.128 & 0.825 & 1.287 \\
\hline Wetland & 19 & 1.284 & 0.036 & 1.225 & 1.344 \\
\hline \multicolumn{6}{|l|}{ LMINLEN } \\
\hline Open & 99 & 1.538 & 0.109 & 1.286 & 1.723 \\
\hline Light cover & 87 & 1.378 & 0.128 & 1.098 & 1.573 \\
\hline Heavy cover & 27 & 1.667 & 0.057 & 1.513 & 1.762 \\
\hline Forest & 54 & 1.361 & 0.135 & 1.057 & 1.541 \\
\hline Wetland & 19 & 1.555 & 0.026 & 1.506 & 1.604 \\
\hline LLENRA8 & \multicolumn{5}{|c|}{ (Log medlen)/(Log fofo) } \\
\hline Open & 99 & 1.218 & 0.039 & 1.123 & 1.302 \\
\hline Light cover & 87 & 1.276 & 0.066 & 1.175 & 1.534 \\
\hline Heavy cover & 27 & 1.216 & 0.029 & 1.158 & 1.264 \\
\hline Forest & 54 & 1.290 & 0.081 & 1.153 & 1.544 \\
\hline Wetland & 19 & 1.232 & 0.049 & 1.133 & 1.289 \\
\hline LLENRA21 & \multicolumn{5}{|c|}{ (Log medlen)/(Log timap) } \\
\hline Open & 99 & 1.139 & 0.015 & 1.108 & 1.18 \\
\hline Light cover & 87 & 1.189 & 0.036 & 1.142 & 1.296 \\
\hline Heavy cover & 27 & 1.138 & 0.016 & 1.099 & 1.168 \\
\hline Forest & 54 & 1.185 & 0.043 & 1.130 & 1.331 \\
\hline Wetland & 19 & 1.159 & 0.018 & 1.127 & 1.192 \\
\hline LMLRAT3 & \multicolumn{5}{|c|}{ (Log tubml)/(Log fofo) } \\
\hline Open & 99 & 1.084 & 0.030 & 0.989 & 1.13 \\
\hline Light cover & 87 & 1.092 & 0.042 & 1.014 & 1.205 \\
\hline Heavy cover & 27 & 1.080 & 0.022 & 1.036 & 1.125 \\
\hline Forest & 54 & 1.098 & 0.050 & 0.998 & 1.257 \\
\hline Wetland & 19 & 1.072 & 0.041 & 0.994 & 1.137 \\
\hline LDEPRA9 & \multicolumn{5}{|c|}{ (Log tarsmlt)/(Log maxsi) } \\
\hline Open & 99 & 1.020 & 0.011 & 0.996 & 1.046 \\
\hline Light cover & 87 & 1.014 & 0.020 & 0.967 & 1.059 \\
\hline Heavy cover & 27 & 1.019 & 0.010 & 0.997 & 1.052 \\
\hline Forest & 54 & 1.030 & 0.017 & 0.993 & 1.067 \\
\hline Wetland & 19 & 1.017 & 0.018 & 0.983 & 1.056 \\
\hline
\end{tabular}


Table 4. Results of four-habitat category astragalus discriminant function analysis.

A. Pooled within-class standardized canonical coefficients

Canonical Discriminant Functions: Standardized by Within Variances

\begin{tabular}{lcccc}
\hline & $\mathbf{1}$ & $\mathbf{2}$ & $\mathbf{3}$ \\
\cline { 2 - 5 } LTARSMLT & 0.990 & & 5.757 & 5.133 \\
LTAMAP & 4.233 & & -3.857 & -1.371 \\
LMINLEN & -4.742 & & -0.505 & -4.273 \\
LLENRA8 & 0.002 & & 1.402 & 0.798 \\
LLENRA21 & -0.053 & -0.044 & -0.637 \\
LMLRAT3 & 0.004 & -0.518 & -0.373 \\
LDEPRA9 & 0.004 & -0.168 & 0.196
\end{tabular}

$\begin{array}{llll}\text { \% Variance } & 71.7 & 19.2 & 9.1\end{array}$

B. Resubstitution classification results from quadratic discriminant function analysis (total correct $=88 \%$ )

Classification Matrix (Cases in row categories classified into columns)

Open

Light Cover

Heavy Cover

Forest

Total

\begin{tabular}{ccccc} 
Open & Light Cover & Heavy Cover & Forest & \% correct \\
\hline 89 & 4 & 6 & 0 & 90 \\
4 & 72 & 5 & 6 & 83 \\
1 & 1 & 25 & 0 & 93 \\
0 & 5 & 0 & 49 & 91 \\
& & & & 88
\end{tabular}

C. Multivariate statistics testing hypothesis that class means are equal.

Test Statistic

\begin{tabular}{lrrrrr} 
Statistic & Value & Approx. F-Ratio & df & p-Value \\
\hline Wilks's Lambda & 0.137 & 35.235 & 21 & 727 & $<0.0001$ \\
Pillai's Trace & 1.330 & 29.482 & 21 & 777 & $<0.0001$ \\
Lawley-Hotelling Trace & 3.343 & 40.703 & 21 & 767 & $<0.0001$
\end{tabular}

D. Jackknifed classification results from quadratic discriminant function analysis (total correct $=84 \%$ )

Jackknifed Classification Matrix

Open

Light Cover

Heavy Cover

Forest

\begin{tabular}{rrrrr} 
& & & & \\
Open & Light Cover & Heavy Cover & Forest & $\%$ correct \\
\hline 86 & 5 & 8 & 0 & 87 \\
4 & 67 & 5 & 11 & 77 \\
2 & 2 & 22 & 1 & 81 \\
0 & 6 & 0 & 48 & 89 \\
& & & & 84
\end{tabular}


Table 5. Results of five habitat category astragalus discriminant function analysis.

A. Pooled within-class standardized canonical coefficients

Canonical Discriminant Functions: Standardized by Within Variances

\begin{tabular}{lcccc} 
& $\mathbf{1}$ & $\mathbf{2}$ & $\mathbf{3}$ & $\mathbf{4}$ \\
\hline LTARSMLT & 1.085 & 4.994 & 4.909 & 7.134 \\
LTAMAP & 4.072 & -3.288 & -1.520 & -2.969 \\
LMINLEN & -4.772 & -0.232 & -3.640 & -4.245 \\
LLENRA8 & -0.081 & 1.284 & 1.090 & 0.103 \\
LLENRA21 & -0.081 & 0.089 & -0.642 & 0.187 \\
LMLRAT3 & 0.050 & -0.564 & -0.459 & -0.724 \\
LDEPRA9 & 0.023 & -0.265 & 0.332 & -1.174
\end{tabular}

\begin{tabular}{lllll}
\hline$\%$ Variance & 68.3 & 22.1 & 8.7 & 0.9
\end{tabular}

B. Resubstitution classification results from quadratic discriminant function analysis (total correct $=87 \%$ ).

Classification Matrix (Cases in row categories classified into columns)

Open Light Cover Heavy Cover Forest Wetland \% correct

$\begin{array}{lcccccc}\text { Open } & 89 & 3 & 6 & 0 & 1 & 90 \\ \text { Light Cover } & 4 & 70 & 1 & 5 & 7 & 80 \\ \text { Heavy Cover } & 1 & 0 & 25 & 0 & 1 & 93 \\ \text { Forest } & 0 & 4 & 0 & 45 & 5 & 83 \\ \text { Wetland } & 0 & 0 & 0 & 0 & 19 & 100 \\ \text { Total } & & & & & & 87\end{array}$

C. Multivariate statistics testing hypothesis that class means are equal.

Test Statistic

\begin{tabular}{lrrrrr} 
Statistic & Value & $\begin{array}{r}\text { Approx. F- } \\
\text { Ratio }\end{array}$ & df & p-Value \\
\hline Wilks's Lambda & 0.125 & 27.652 & 28 & 992 & $<0.0001$ \\
Pillai's Trace & 1.399 & 21.362 & 28 & 1,112 & $<0.0001$ \\
Lawley-Hotelling Trace & 3.470 & 33.891 & 28 & 1,094 & $<0.0001$
\end{tabular}

D. Jackknifed classification results from quadratic discriminant function analysis (total correct $=82 \%$ )

\section{Jackknifed Classification Matrix}

Open Light Cover Heavy Cover Forest Wetland \% correct

\begin{tabular}{lcccccc}
\hline Open & 86 & 4 & 8 & 0 & 1 & 87 \\
Light Cover & 4 & 65 & 1 & 10 & 7 & 75 \\
Heavy Cover & 2 & 1 & 22 & 1 & 1 & 81 \\
Forest & 0 & 5 & 0 & 44 & 5 & 81 \\
Wetland & 0 & 1 & 0 & 1 & 17 & 89 \\
Total & & & & & & 82
\end{tabular}


Table 6. Classification errors of the 4- and 5-habitat discriminant function models. Mixed sex body mass (in kg.) data from Kappelman et al. (1997) and Kingdon (1997).

\begin{tabular}{|c|c|c|c|c|c|c|c|c|c|}
\hline \multirow[b]{2}{*}{ Taxon } & \multirow[b]{2}{*}{$\begin{array}{l}\text { Body } \\
\text { Mass } \\
(\mathrm{kg})\end{array}$} & \multirow[b]{2}{*}{$\begin{array}{l}\text { Habitat } \\
\text { Category }\end{array}$} & \multirow[b]{2}{*}{$\begin{array}{l}\text { Total } \\
\text { Sample }\end{array}$} & \multicolumn{3}{|c|}{ 4-habitat category model } & \multicolumn{3}{|c|}{ 5-habitat category model } \\
\hline & & & & $\begin{array}{l}\text { Number } \\
\text { Misclassified }\end{array}$ & $\begin{array}{l}\text { Percent } \\
\text { Misclassified }\end{array}$ & $\begin{array}{l}\text { Most Likely } \\
\text { Reclassification }\end{array}$ & $\begin{array}{l}\text { Number } \\
\text { Misclassified }\end{array}$ & $\begin{array}{l}\text { Percent } \\
\text { Misclassified }\end{array}$ & $\begin{array}{l}\text { Most Likely } \\
\text { Reclassification }\end{array}$ \\
\hline Alcelaphus buselaphus & 155 & Open & 14 & 0 & $0 \%$ & & 0 & $0 \%$ & \\
\hline Damaliscus dorcas & 68 & Open & 8 & 0 & $0 \%$ & & 0 & $0 \%$ & \\
\hline Damaliscus Iunatus & 136 & Open & 10 & 0 & $0 \%$ & & 0 & $0 \%$ & \\
\hline Connochaetes taurinus & 214 & Open & 6 & 0 & $0 \%$ & & 0 & $0 \%$ & \\
\hline Connochaetes gnou & 148 & Open & 5 & 0 & $0 \%$ & & 0 & $0 \%$ & \\
\hline Hippotragus niger & 228 & Open & 9 & 3 & $33 \%$ & Heavy cover & 3 & $33 \%$ & Heavy Cover \\
\hline Addax nasomaculatus & 96 & Open & 4 & 2 & $50 \%$ & Light cover & 2 & $50 \%$ & Light Cover, Wetland \\
\hline Oryx gazella & 169 & Open & 13 & 3 & $23 \%$ & Heavy cover & 3 & $23 \%$ & Heavy Cover \\
\hline Hippotragus equinus & 270 & Open & 4 & 0 & $0 \%$ & & 0 & $0 \%$ & \\
\hline Antidorcas marsupialis & 38 & Open & 8 & 0 & $0 \%$ & & 0 & $0 \%$ & \\
\hline Gazella thomsoni & 21 & Open & 8 & 1 & $13 \%$ & Light cover & 1 & $13 \%$ & Light Cover \\
\hline Gazella granti & 55 & Open & 10 & 1 & $10 \%$ & Light cover & 1 & $10 \%$ & Light Cover \\
\hline Sylvicapra grimmia & 20 & Light Cover & 17 & 3 & $18 \%$ & Forest & 3 & $18 \%$ & Forest \\
\hline Aepyceros melampus & 53 & Light Cover & 12 & 3 & $25 \%$ & Open & 4 & $33 \%$ & Open \\
\hline Ourebia ourebia & 17 & Light Cover & 7 & 0 & $0 \%$ & & 0 & $0 \%$ & \\
\hline Raphicerus campestris & 11 & Light Cover & 5 & 0 & $0 \%$ & & 0 & $0 \%$ & \\
\hline Madoqua kirkii & 5 & Light Cover & 11 & 2 & $18 \%$ & Forest & 2 & $18 \%$ & Forest \\
\hline Kobus kob & 79 & Light Cover & 10 & 4 & $40 \%$ & Heavy cover & 5 & $50 \%$ & Wetland \\
\hline Redunca redunca & 45 & Light Cover & 10 & 1 & $10 \%$ & Forest & 1 & $10 \%$ & Wetland \\
\hline Redunca arundinum & 58 & Light Cover & 7 & 2 & $29 \%$ & Heavy cover, Open & 2 & $29 \%$ & Open, Wetland \\
\hline Redunca fulvorufula & 30 & Light Cover & 8 & 0 & $0 \%$ & & 0 & $0 \%$ & \\
\hline Tragelaphus euryceros & 270 & Heavy Cover & 6 & 0 & $0 \%$ & & 0 & $0 \%$ & \\
\hline Tragelaphus strepsiceros & 214 & Heavy Cover & 7 & 1 & $14 \%$ & Open & 1 & $14 \%$ & Open \\
\hline Tragelaphus imberbis & 82 & Heavy Cover & 4 & 1 & $25 \%$ & Light cover & 1 & $25 \%$ & Wetland \\
\hline Kobus ellipsiprymnus & 210 & Heavy Cover & 10 & 0 & $0 \%$ & & 0 & $0 \%$ & \\
\hline Tragelaphus scriptus & 43 & Forest & 17 & 1 & $6 \%$ & Light cover & 3 & $18 \%$ & Wetland \\
\hline Cephalophus natalensis & 13 & Forest & 4 & 0 & $0 \%$ & & 0 & $0 \%$ & \\
\hline Cephalophus leucogaster & 18 & Forest & 4 & 0 & $0 \%$ & & 0 & $0 \%$ & \\
\hline Cephalophus silvicultor & 63 & Forest & 7 & 2 & $29 \%$ & Light cover & 4 & $57 \%$ & Wetland, Light Cover \\
\hline Cephalophus monticola & 6 & Forest & 4 & 0 & $0 \%$ & & 0 & $0 \%$ & \\
\hline Cephalophus nigrifrons & 16 & Forest & 4 & 2 & $50 \%$ & Light cover & 2 & $50 \%$ & Light Cover \\
\hline Cephalophus weynsi & 20 & Forest & 5 & 0 & $0 \%$ & & 0 & $0 \%$ & \\
\hline Cephalophus dorsalis & 22 & Forest & 5 & 0 & $0 \%$ & & 0 & $0 \%$ & \\
\hline Neotragus moschatus & 5 & Forest & 4 & 0 & $0 \%$ & & 0 & $0 \%$ & \\
\hline Kobus megaceros & 90 & Wetland & 7 & & & & 0 & $0 \%$ & \\
\hline Kobus leche & 90 & Wetland & 1 & & & & 0 & $0 \%$ & \\
\hline Tragelaphus spekei & 78 & Wetland & 11 & & & & 0 & $0 \%$ & \\
\hline Total misclassified & & & 286 & 32 & & & 38 & & \\
\hline
\end{tabular}


Table 7. Results of the 4- and 5-habitat category discriminant function analyses of Omo Shungura Formation antelope astragali, shown by Member. Temporal midpoints from Bobe et al., (2002).

$\begin{array}{llllllll}\text { Member } & \text { B } & \text { C } & \text { D } & \text { E } & \text { F } & \text { G Lower } & \text { G Upper }\end{array}$

\begin{tabular}{llllllll} 
Temporal Midpoint & $3.0 \mathrm{Ma}$ & $2.65 \mathrm{Ma}$ & $2.45 \mathrm{Ma}$ & $2.4 \mathrm{Ma}$ & $2.35 \mathrm{Ma}$ & $2.2 \mathrm{Ma}$ & $2.0 \mathrm{Ma}$ \\
\hline
\end{tabular}

4-Habitat Model

\begin{tabular}{lccccccc}
\hline Open & 1 & 4 & 3 & 6 & 10 & 15 & 3 \\
Light Cover & 4 & 11 & 2 & 9 & 8 & 27 & 4 \\
Heavy Cover & 8 & 35 & 10 & 15 & 22 & 88 & 10 \\
Forest & 2 & 8 & 6 & 5 & 13 & 49 & 3
\end{tabular}

5-Habitat Model

\begin{tabular}{lccccccc}
\hline Open & 1 & 4 & 3 & 6 & 10 & 15 & 2 \\
Light Cover & 3 & 11 & 2 & 9 & 8 & 25 & 4 \\
Heavy Cover & 8 & 33 & 8 & 14 & 20 & 80 & 10 \\
Forest & 2 & 7 & 6 & 4 & 12 & 42 & 3 \\
Wetland & 1 & 3 & 2 & 2 & 3 & 17 & 0 \\
\hline Total $n$ & 15 & 58 & 21 & 35 & 53 & 179 & 20
\end{tabular}


Table 8. Results of the 4-habitat category discriminant function analysis of Omo Shungura Formation antelope astragali for the entire sample, shown by Member and Unit.

\begin{tabular}{|c|c|c|c|c|c|c|c|c|c|c|c|c|c|}
\hline Member & Unit & $\begin{array}{l}\frac{\subsetneq}{\Phi} \\
\stackrel{0}{0}\end{array}$ & 蒙 & 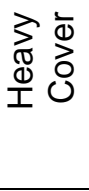 & $\begin{array}{l}\text { ष्ठ } \\
\overline{0} \\
\dot{0}\end{array}$ & $\begin{array}{l}\bar{\pi} \\
\stackrel{0}{0}\end{array}$ & Member & Unit & & J & 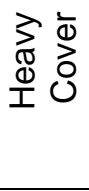 & 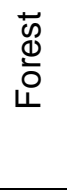 & $\begin{array}{l}\bar{\pi} \\
0\end{array}$ \\
\hline A & 3 & 1 & & & & 1 & $G$ & 1 & 1 & 2 & 6 & 4 & 13 \\
\hline A Total & & 1 & & & & 1 & & 3 & 1 & & 4 & 5 & 10 \\
\hline \multirow{5}{*}{ B } & 2 & & & 1 & & 1 & & 4 & 3 & 4 & 6 & 1 & 14 \\
\hline & 9 & & & & 1 & 1 & & 5 & 1 & 1 & 8 & 2 & 12 \\
\hline & 10 & & 2 & 4 & & 6 & & 6 & & 2 & 4 & 1 & 7 \\
\hline & 11 & 1 & 2 & 1 & 1 & 5 & & 7 & 1 & 1 & 4 & 4 & 10 \\
\hline & 12 & & & 2 & & 2 & & 8 & 2 & 1 & 32 & 19 & 54 \\
\hline B Total & & 1 & 4 & 8 & 2 & 15 & & 9 & & & 2 & 1 & 3 \\
\hline \multirow[t]{6}{*}{ C } & 4 & & 4 & 2 & & 6 & & 10 & & & 3 & & 3 \\
\hline & 5 & & 1 & 4 & 1 & 6 & & 11 & 1 & 1 & & 1 & 3 \\
\hline & 6 & 1 & 3 & 8 & 1 & 13 & & 12 & 5 & 11 & 16 & 9 & 41 \\
\hline & 7 & & & 2 & 1 & 3 & & 13 & & 4 & 3 & 2 & 9 \\
\hline & 8 & 2 & 3 & 17 & 5 & 27 & & 15 & & 2 & 2 & & 4 \\
\hline & 9 & 1 & & 2 & & 3 & & 19 & 1 & 1 & 4 & 3 & 9 \\
\hline C Total & & 4 & 11 & 35 & 8 & 58 & & 24 & 1 & 1 & & & 2 \\
\hline \multirow[t]{7}{*}{ D } & & & 1 & 1 & & 2 & & 27 & 1 & & 4 & & 5 \\
\hline & 0 & 1 & & & & 1 & & 28 & 2 & & 10 & 1 & 13 \\
\hline & 1 & & & 2 & 2 & 4 & G Total & & 20 & 31 & 108 & 53 & 212 \\
\hline & 2 & & & 1 & & 1 & $\mathrm{H}$ & 2 & 1 & & 2 & & 3 \\
\hline & 3 & & 1 & & 2 & 3 & & 4 & 1 & 1 & 2 & & 4 \\
\hline & 4 & & & 2 & 1 & 3 & H Total & & 2 & 1 & 4 & & 7 \\
\hline & 5 & 2 & & 4 & 1 & 7 & $J$ & 2 & & & 1 & & 1 \\
\hline D Total & & 3 & 2 & 10 & 6 & 21 & & 6 & 1 & & 4 & 1 & 6 \\
\hline \multirow[t]{5}{*}{$E$} & 1 & & 2 & 1 & & 3 & J Total & & 1 & & 5 & 1 & 7 \\
\hline & 2 & & & & 1 & 1 & $\mathrm{~K}$ & & & & & 1 & 1 \\
\hline & 3 & 3 & 5 & 6 & 1 & 15 & & 1 & & & 1 & & 1 \\
\hline & 4 & 3 & & 6 & 3 & 12 & K Total & & & & 1 & 1 & 2 \\
\hline & 5 & & 2 & 2 & & 4 & $L$ & 8 & 1 & & & & 1 \\
\hline E Total & & 6 & 9 & 15 & 5 & 35 & & 9 & & 1 & & & 1 \\
\hline \multirow[t]{6}{*}{$F$} & & 1 & 1 & 1 & 2 & 5 & L Total & & 1 & 1 & & & 2 \\
\hline & 0 & 4 & 1 & 11 & 2 & 18 & & & & & & & \\
\hline & 1 & 4 & 6 & 6 & 4 & 20 & & & & & & & \\
\hline & 2 & & & 1 & & 1 & & & & & & & \\
\hline & 3 & 1 & & 3 & 3 & 7 & & & & & & & \\
\hline & 5 & & & & 2 & 2 & & & & & & & \\
\hline F Total & & 10 & 8 & 22 & 13 & 53 & Grand & Total & 49 & 67 & 208 & 89 & 413 \\
\hline
\end{tabular}


Table 9. The correlation coefficient $(R)$ and the adjusted coefficient of determination $\left(R^{2}\right)$ between the log of femoral length and the log of variables used in this study.

\begin{tabular}{lcccc}
\hline Caliper Measurements & $\boldsymbol{n}$ & $\boldsymbol{R}$ & $\begin{array}{c}\text { Adjusted } \\
\boldsymbol{R}^{\mathbf{2}}\end{array}$ & $\boldsymbol{p}$ \\
\hline LTARSMLT & 177 & 0.980 & 0.961 & $<0.0001$ \\
LTAMAP & 177 & 0.965 & 0.932 & $<0.0001$ \\
LMINLEN & 177 & 0.987 & 0.974 & $<0.0001$
\end{tabular}

\section{Ratios}

$\begin{array}{lcccc}\text { LLENRA8 } & 177 & 0.778 & 0.603 & <0.0001 \\ \text { LLENRA21 } & 177 & 0.815 & 0.663 & <0.0001 \\ \text { LLMLRAT3 } & 177 & 0.464 & 0.211 & <0.0001 \\ \text { LDEPRA9 } & 177 & 0.018 & 3 \mathrm{E}-004 & 0.8100\end{array}$


Table 10. Table showing the relative frequency of Antilopini, Alcelaphini, and Hippotragini (AAH) as a proportion of the total sample of antelopes identifiable to tribe from each member of the Omo Shungura Formation, compared to the percentage of open habitat ecomorphs determined by this study. Taxonomic identifications are based on craniodental material. Data for AAH and temporal midpoints from Bobe et al., (2002).

\begin{tabular}{lcccrrrr}
$\begin{array}{c}\text { Formation } \\
\text { Member or unit }\end{array}$ & Alcelaphini & Antilopini & Hippotragini & $\begin{array}{c}\text { total } \\
\text { Antelopes }\end{array}$ & $\begin{array}{c}\text { percent } \\
\text { AAH }\end{array}$ & $\begin{array}{c}\text { percent } \\
\text { OPEN }\end{array}$ & $\begin{array}{c}\text { Temporal } \\
\text { Midpoint } \\
\text { (Ma) }\end{array}$ \\
\hline Shungura B(U) & 7 & 1 & 0 & 176 & $4.5 \%$ & $7 \%$ & 2.9 \\
Shungura C & 5 & 3 & 3 & 430 & $2.6 \%$ & $7 \%$ & 2.7 \\
Shungura D & 6 & 1 & 0 & 174 & $4.0 \%$ & $14 \%$ & 2.5 \\
Shungura E & 9 & 0 & 1 & 287 & $3.5 \%$ & $17 \%$ & 2.4 \\
Shungura F & 25 & 5 & 0 & 342 & $8.8 \%$ & $19 \%$ & 2.36 \\
Shungura G(L) & 51 & 4 & 2 & 1615 & $3.5 \%$ & $8 \%$ & 2.2 \\
Shungura G(U) & 13 & 9 & 0 & 79 & $27.8 \%$ & $15 \%$ & 2 \\
Shungura H & 12 & 3 & 0 & 153 & $9.8 \%$ & $18 \%$ & 1.8 \\
Shungura J-L & 34 & 3 & 0 & 167 & $22.2 \%$ & $18 \%$ & 1.5
\end{tabular}


East

Africa

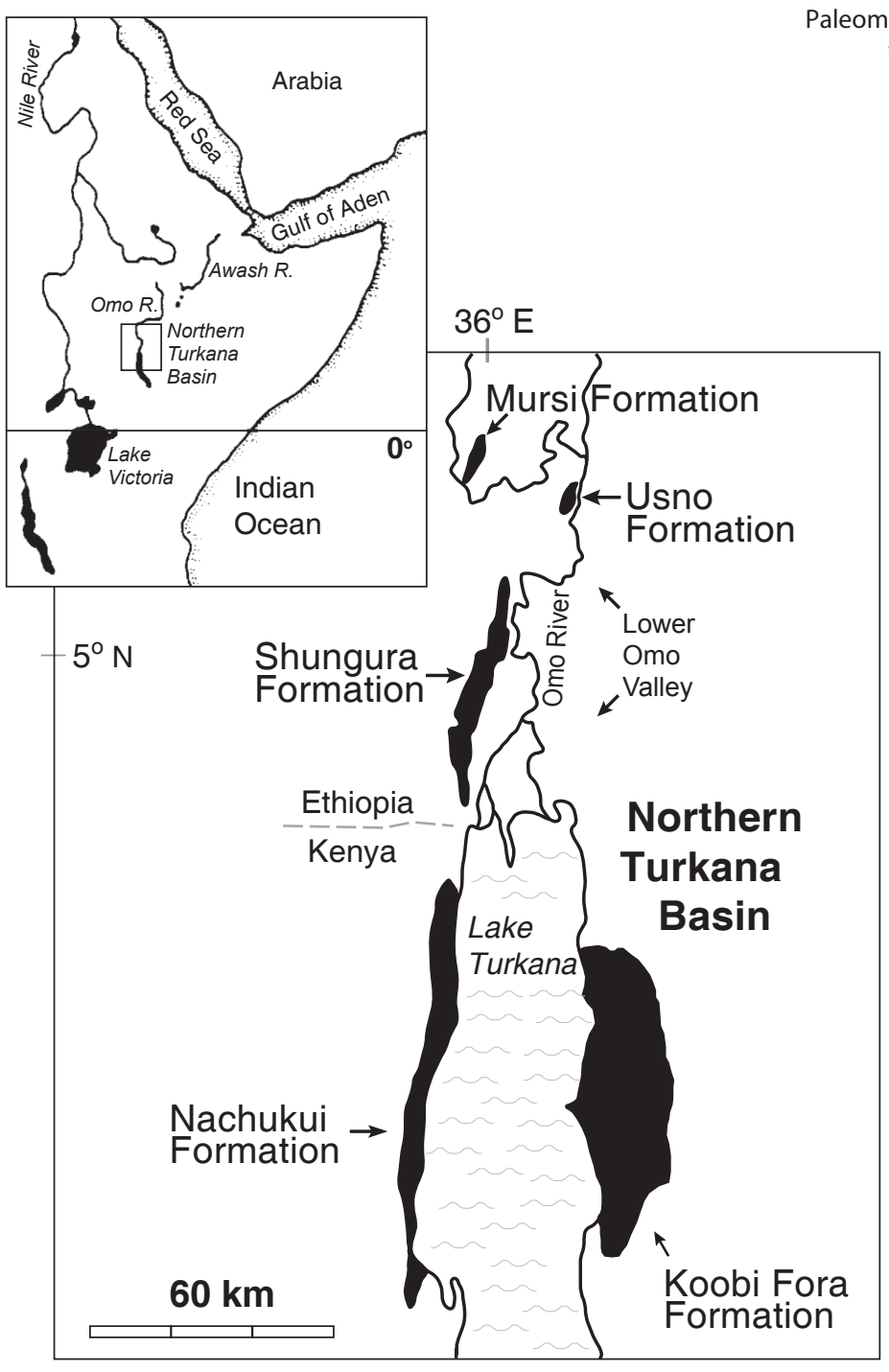

Shungura

Formation

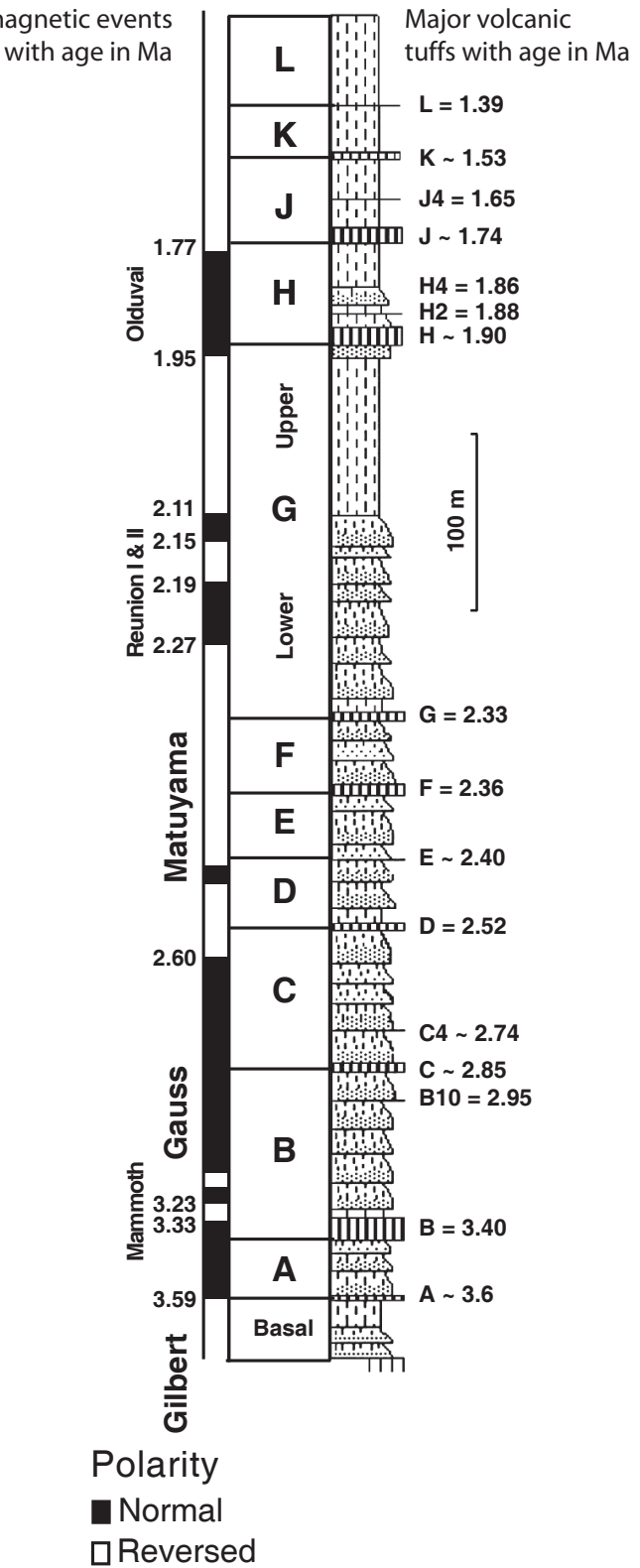

Lithology

ri, Siltstone/Claystone

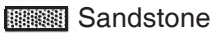

IIIIIIII Tuff 

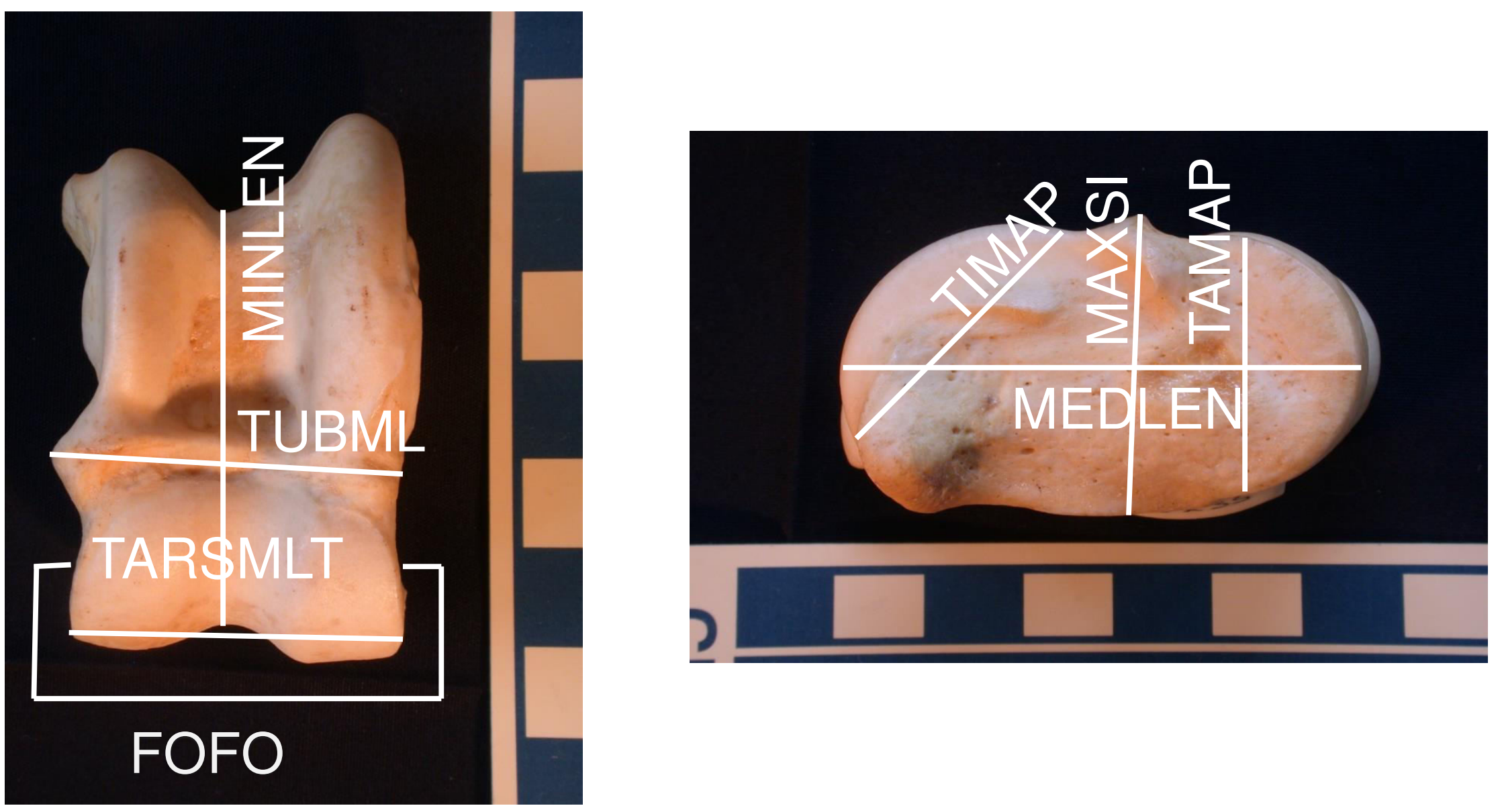

b.

a.

. 


\section{Figure 4}

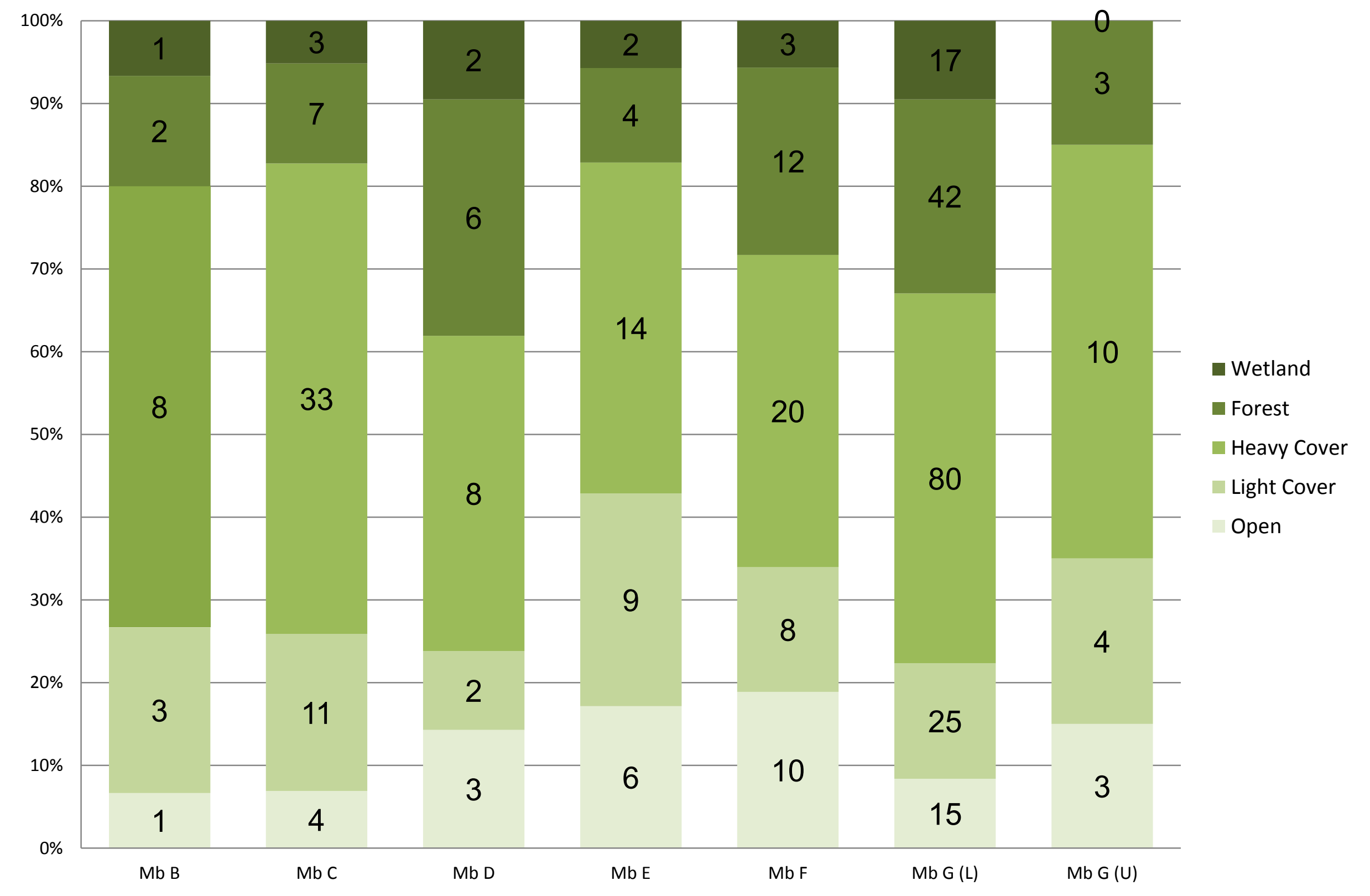




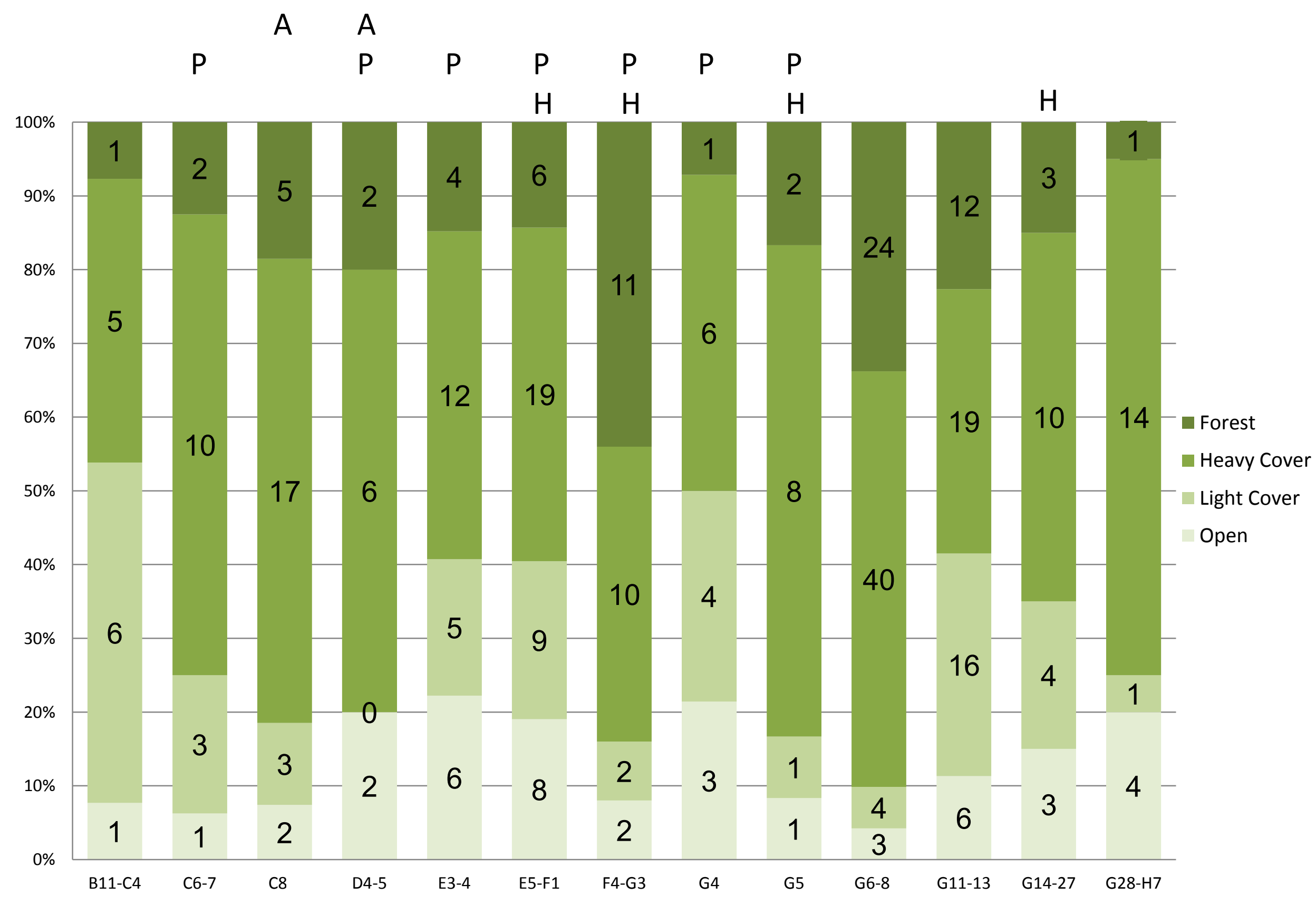




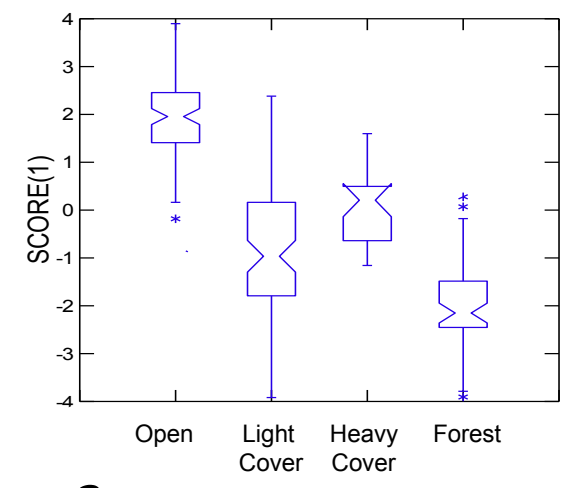

a.

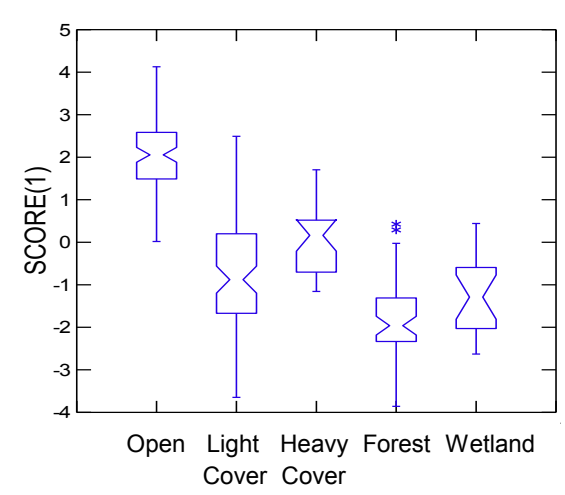

d.

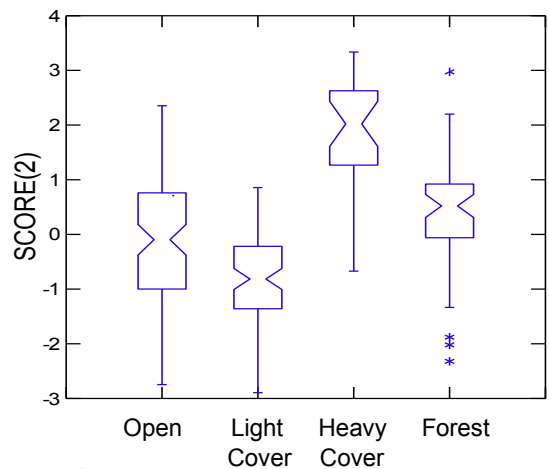

b.

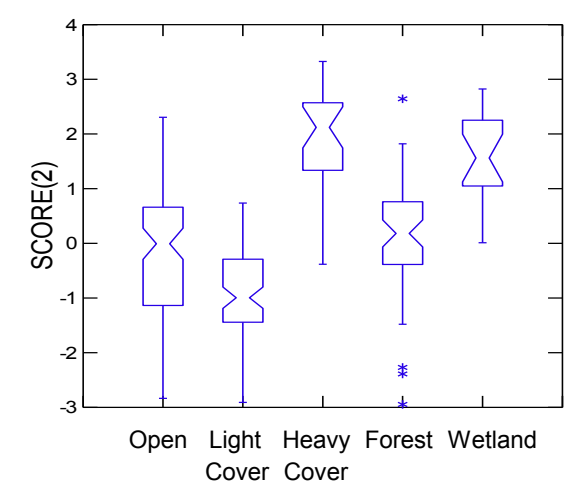

e. HABITAT

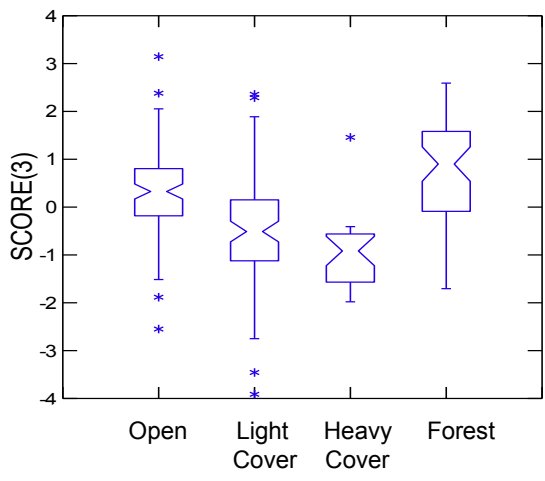

C.

HABITAT

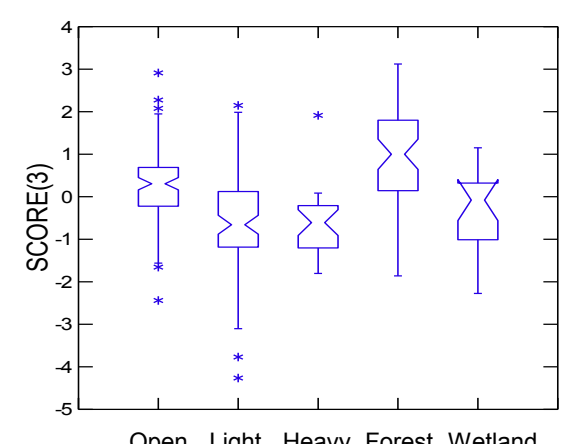

Open Light Heavy Forest Wetland

f. HABITAT

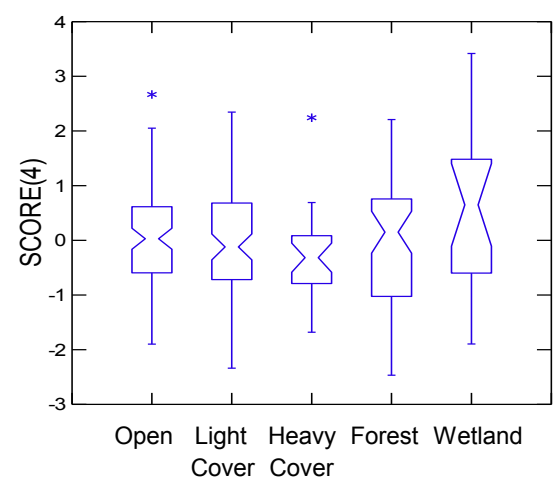

g.

HABITAT 
Divergence

Convergence

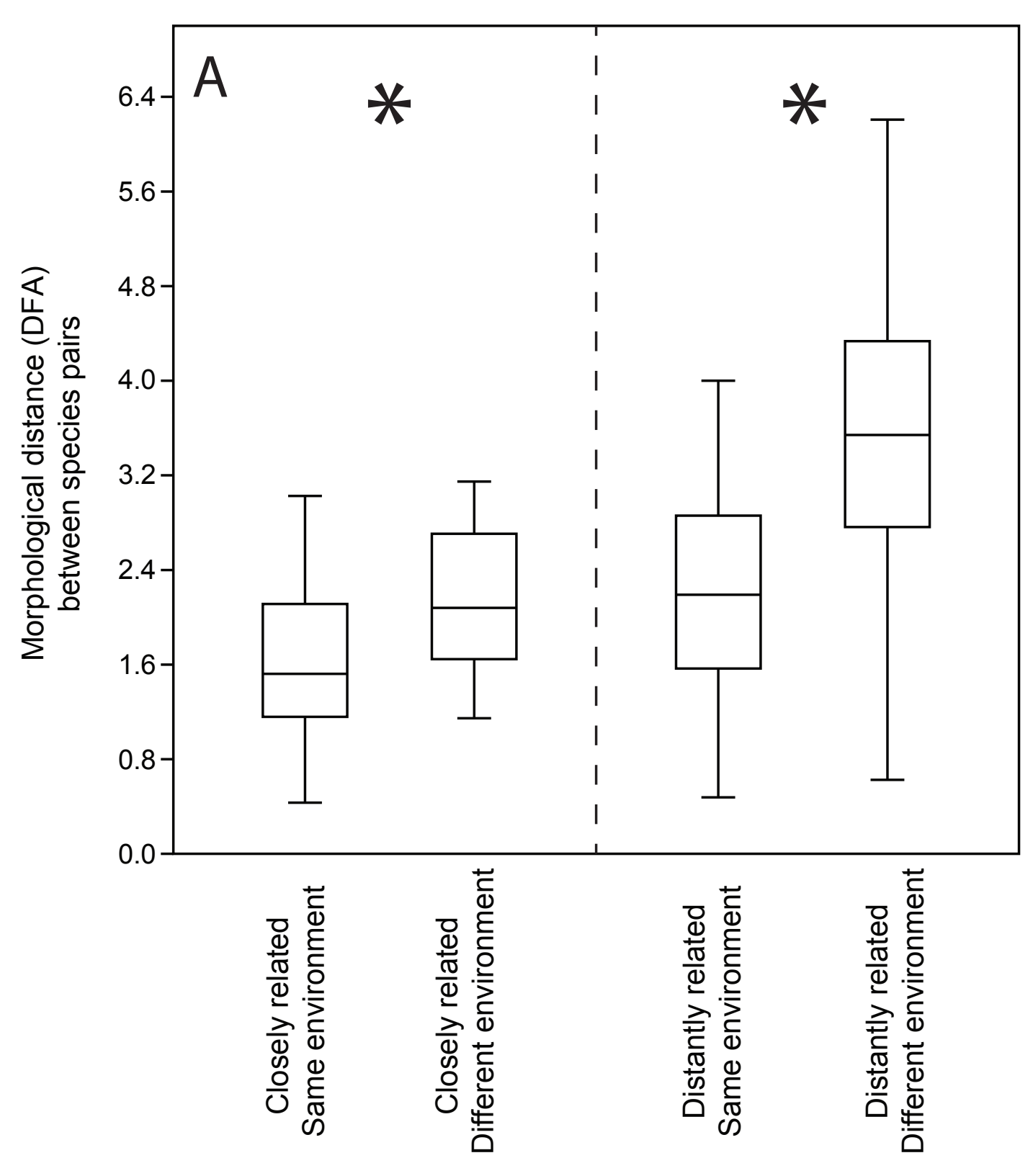

Divergence

Convergence

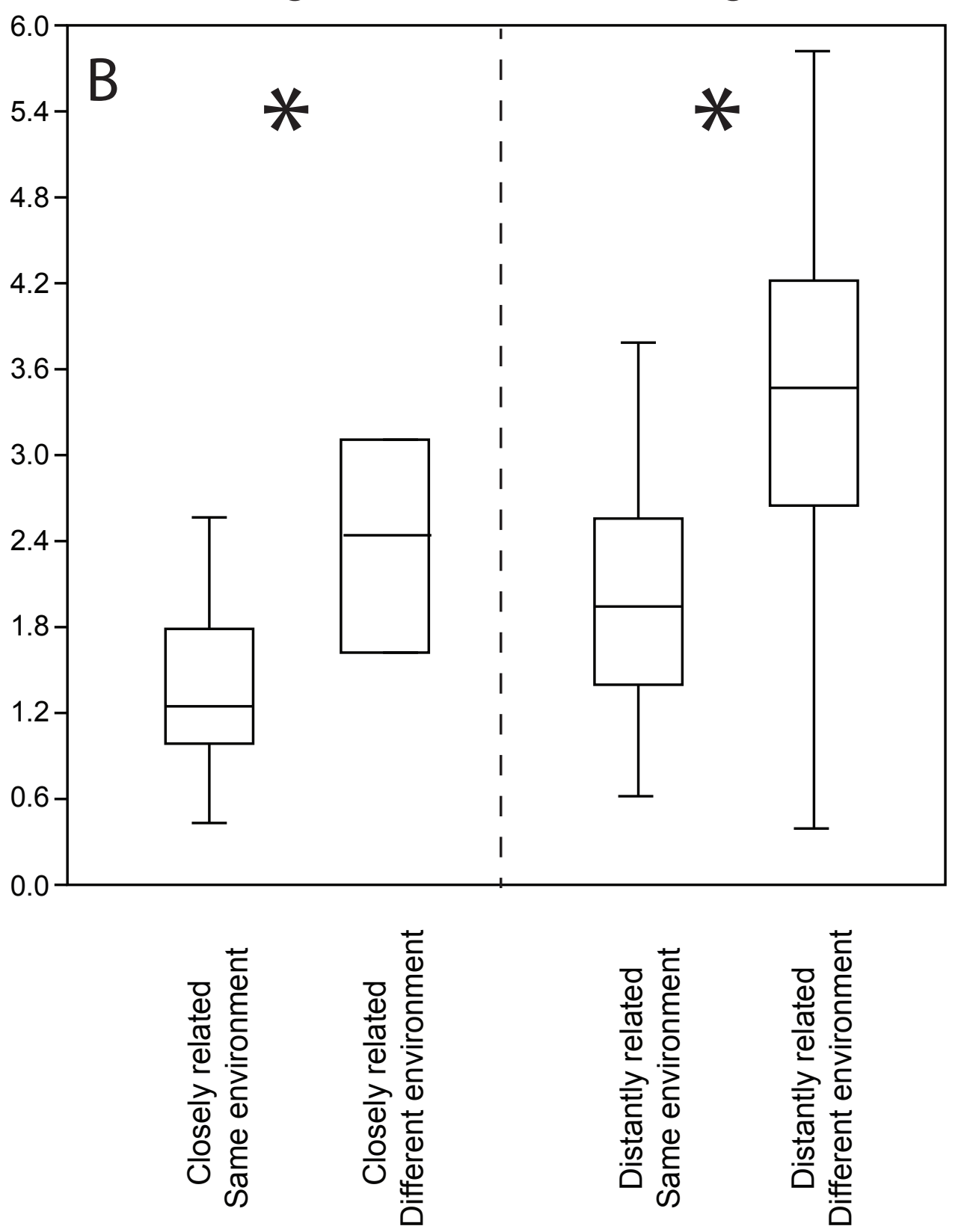



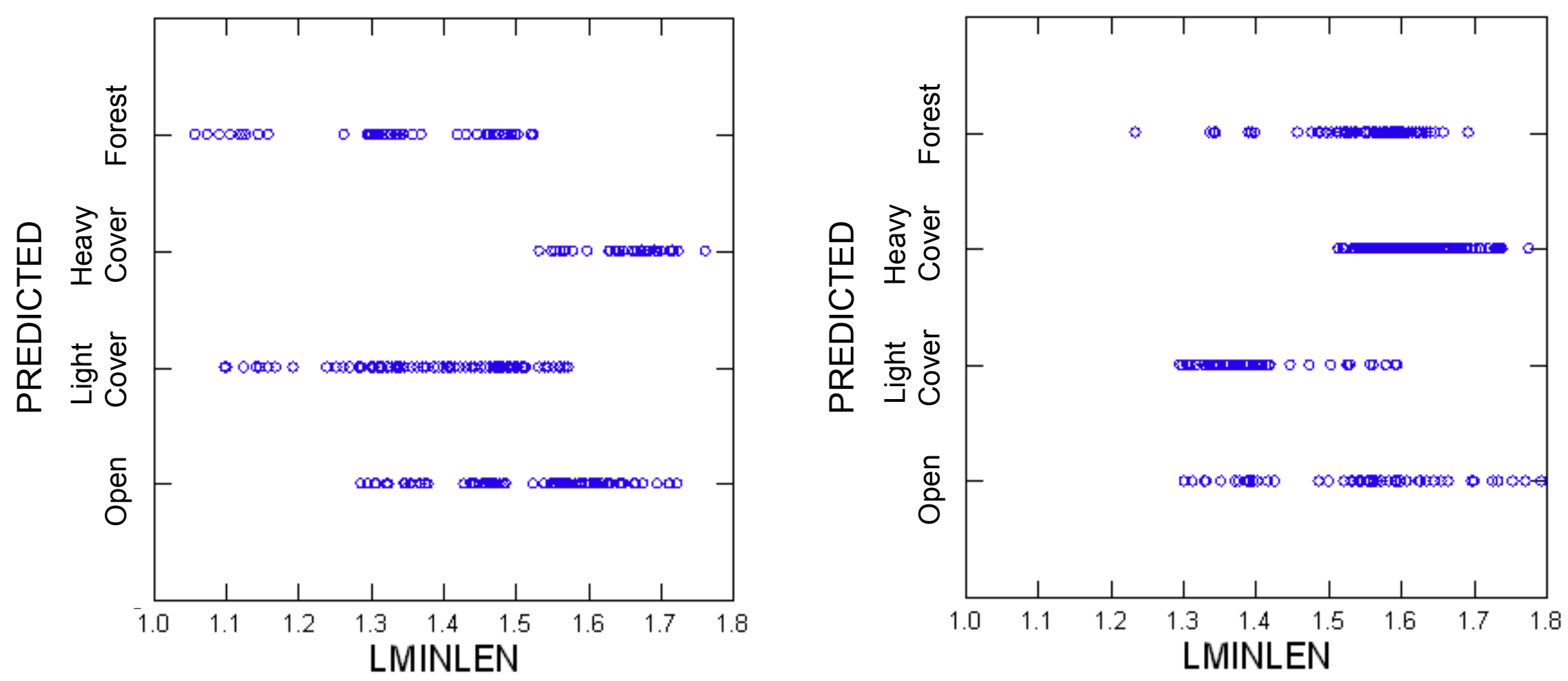

a.

b. 
a.

Shungura Formation with GPTS and dated tuffs in $\mathrm{Ma}$

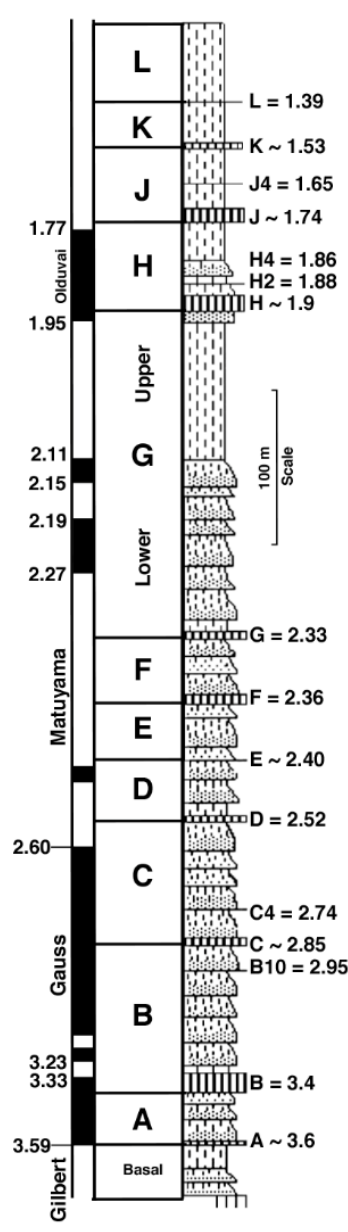

Lithology

[','W Siltstone/Claystone 期雨霜 Sandstone

IIIIIIII Tuff

Polarity

Normal

Reversed b.

c.

d.

e.

f.

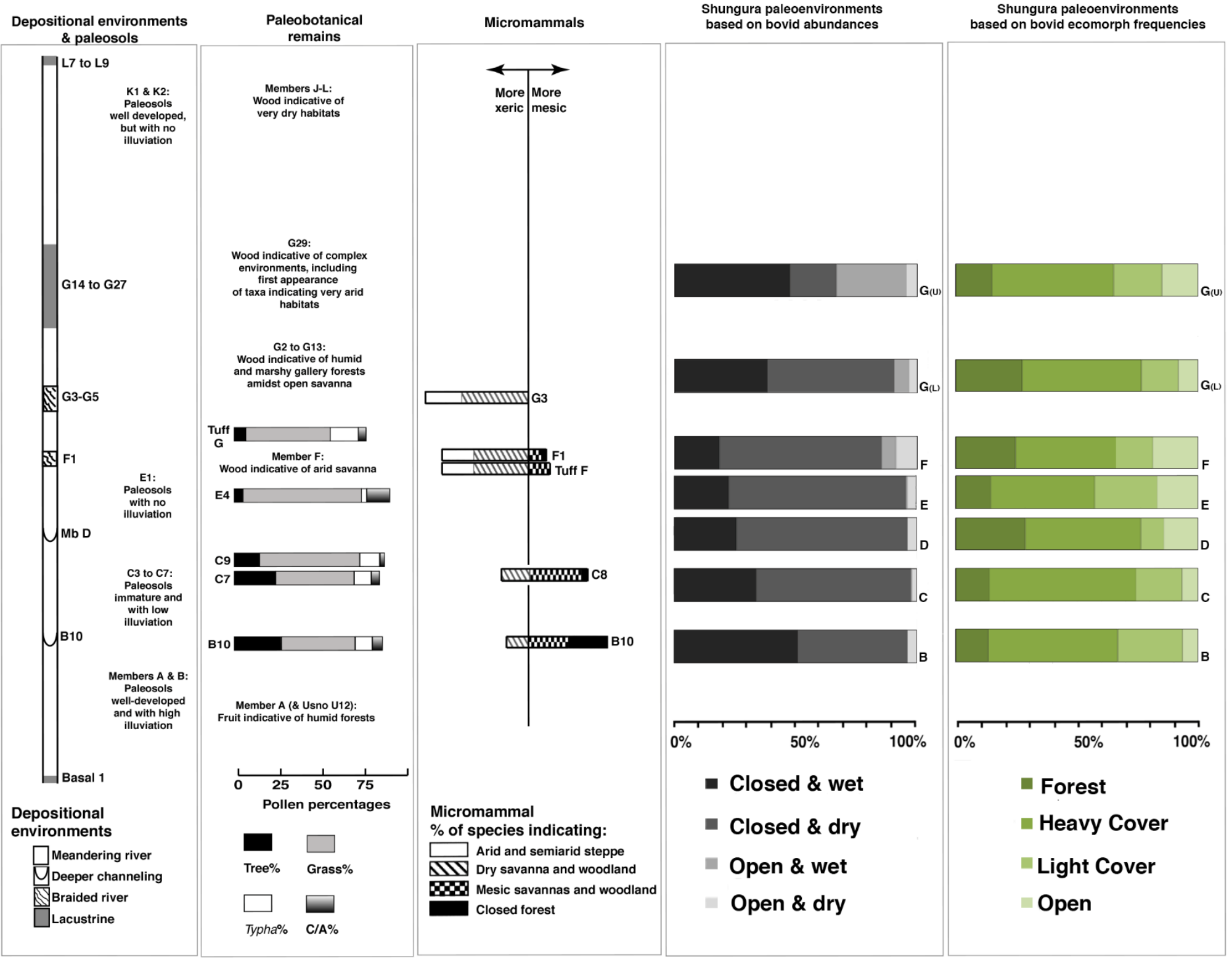

